\title{
Investigating developmental cardiovascular biomechanics and the origins of congenital heart defects
}

\author{
William J. Kowalski ${ }^{1,2}$, Kerem Pekkan ${ }^{3}$, Joseph P. Tinney ${ }^{1,2}$ and Bradley B. Keller ${ }^{1,2,3 *}$ \\ ${ }^{1}$ Cardiovascular Innovation Institute, University of Louisville, Louisville, KY, USA \\ 2 Department of Pediatrics, University of Louisville, Louisville, KY, USA \\ ${ }^{3}$ Department of Biomedical Engineering, Carnegie Mellon University, Pittsburgh, PA, USA
}

Edited by:

Kersti K. Linask, University of South

Florida Morsani College of

Medicine, USA

Reviewed by:

Jörg Männer,

Georg-August-University of

Göttingen, Germany

James C. Huhta, All Children's

Hospital/Pediatric Cardiology

Associates, USA

\section{${ }^{*}$ Correspondence:}

Bradley B. Keller, Division of

Pediatric Heart Research,

Cardiovascular Innovation Institute,

Vice Chair for Research, Department

of Pediatrics, University of

Louisville, 302 East Muhammad Ali

Blvd, Louisville, KY 40202, USA

e-mail: brad.keller@louisville.edu
Innovative research on the interactions between biomechanical load and cardiovascular (CV) morphogenesis by multiple investigators over the past 3 decades, including the application of bioengineering approaches, has shown that the embryonic heart adapts both structure and function in order to maintain cardiac output to the rapidly growing embryo. Acute adaptive hemodynamic mechanisms in the embryo include the redistribution of blood flow within the heart, dynamic adjustments in heart rate and developed pressure, and beat to beat variations in blood flow and vascular resistance. These biomechanically relevant events occur coincident with adaptive changes in gene expression and trigger adaptive mechanisms that include alterations in myocardial cell growth and death, regional and global changes in myocardial architecture, and alterations in central vascular morphogenesis and remodeling. These adaptive mechanisms allow the embryo to survive these biomechanical stresses (environmental, maternal) and to compensate for developmental errors (genetic). Recent work from numerous laboratories shows that a subset of these adaptive mechanisms is present in every developing multicellular organism with a "heart" equivalent structure. This chapter will provide the reader with an overview of some of the approaches used to quantify embryonic CV functional maturation and performance, provide several illustrations of experimental interventions that explore the role of biomechanics in the regulation of $\mathrm{CV}$ morphogenesis including the role of computational modeling, and identify several critical areas for future investigation as available experimental models and methods expand.

Keywords: biomechanics, cardiovascular development, computational modeling, congenital heart disease, embryo, hemodynamics

\section{INTRODUCTION}

The heart and vasculature is the first organ system to form and the only one which is required to function successfully throughout embryonic and fetal life for survival (Burggren and Keller, 1998). It is also the organ system where congenital defects are associated with the highest incidence and morbidity and mortality and adult onset diseases are the greatest cause of medical costs and mortality (Go et al., 2013). In the US, congenital heart disease (CHD) occurs in at least 8 of every 1000 live births and accounts for more than $24 \%$ of birth defect related infant deaths (Go et al., 2013). Due to this prevalence, cardiovascular (CV) morphogenesis and the origins of CHD have been widely researched for centuries. This work has uncovered a variety of molecular and cellular mechanisms, morphogenetic and structural processes, and biomechanical cues responsible for the formation of the CV. In turn, this understanding has enabled dramatic advances in the treatment and management of $\mathrm{CHD}$, improving survival rates to $90 \%$ and resulting in over 1 million adults with successfully treated CHD in the US alone.

$\mathrm{CV}$ development is highly conserved among vertebrate species. As a result, a variety of animal models are employed to study CV development based on the unique technologies employed and the questions to be answered. These models include the zebrafish, frog, chick, and mouse (Nieuwkoop and Faber, 1994; Lohr and Yost, 2000; Isogai et al., 2001; Glickman and Yelon, 2002; Levine et al., 2003; Martinsen, 2005; Bruneau, 2008; Savolainen et al., 2009; Al Naieb et al., 2012). In the vertebrate embryo, bilateral endocardial tubes fuse at the ventral midline of the embryo to form the primitive linear heart tube, which begins to beat. Cardiac looping transforms the heart into a looped tube while later events include the formation of endocardial cushions, septation, ventricular trabeculation, and remodeling of the heart valves. Both avians and mammals develop a fully septated, four-chambered heart. A comparative timeline among vertebrate species is given in Table 1. Frog embryos are staged according to Nieuwkoop-Faber (NF) and chick embryos according to Hamburger-Hamilton (HH) (Hamburger and Hamilton, 1951; Nieuwkoop and Faber, 1994).

As blood flows through the vascular system, it exerts normal force due to pressure, circumferential stress due to vessel deformation under pressure, and a tangential wall shear stress (WSS) due to pulsatile blood flow. Over a century ago, based on observations of chick embryos, Thoma proposed that these forces influence vascular morphology (Thoma, 1893). Since that 
Table 1 | Comparative timeline of events in cardiovascular development expressed as days post fertilization.

\begin{tabular}{|c|c|c|c|c|c|}
\hline & Zebrafish & Frog (NF stages) & Mouse & Chick (HH stages) & Human (Carnegie) \\
\hline Gestation/Incubation period & & & 20 days & 21 days & 9 months \\
\hline Linear heart tube & 1 & $1.67(32)$ & 8 & $1.29(9)$ & $28(10)$ \\
\hline Onset of blood flow & 1 & $1.83(33)$ & 8.5 & $1.46(10)$ & $29(11)$ \\
\hline Cardiac looping & $1-2$ & $1.67-2.75(32-40)$ & 8-10.5 & $1.46-4(10-24)$ & 28-32 (10-13) \\
\hline Ventricular septation & & & $9-14$ & $2.42-8(17-34)$ & 30-46 (12-19) \\
\hline Atrioventricular cushions form & 2 & $2.33(39)$ & 10 & $2.23(16)$ & $32(13)$ \\
\hline Outflow tract cushions form & & $2.33(39)$ & 10 & $3.23(19)$ & $32(13)$ \\
\hline
\end{tabular}

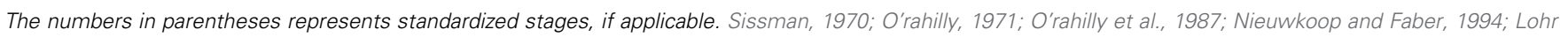
and Yost, 2000; Isogai et al., 2001; Glickman and Yelon, 2002; Levine et al., 2003; Martinsen, 2005; Bruneau, 2008; Savolainen et al., 2009; O'rahilly and Muller, 2010; Al Naieb et al., 2012.

time, vascular adaptation in response to blood flow, or the "flow dependency principle" has been established in the mature CV system (Kamiya and Togawa, 1980). Increased transmural stress due to hypertension elicits a remodeling response including wall thickening, increased smooth muscle proliferation, and increased collagen production and turnover (Nissen et al., 1978; Olivetti et al., 1980; Fung and Liu, 1991; Tedgui et al., 1992; Intengan et al., 1999a,b). Experiments in a variety of species to alter blood flow within vessels demonstrate that increased flow results in increased diameter and decreased flow results in decreased diameter or vessel regression (Kamiya and Togawa, 1980; Guyton and Hartley, 1985; Langille and O'donnell, 1986; Girerd et al., 1996; Bayer et al., 1999; Gruionu et al., 2005). Mural growth and remodeling act to return wall stress to normal values (Fung and Liu, 1991) while luminal growth returns WSS to levels experienced prior to the flow alteration (Kamiya and Togawa, 1980; Langille and O'donnell, 1986). It is thought that hemodynamic forces deform the vascular wall and in particular the endothelial cells, which respond by transducing biochemical signals leading to morphological and structural changes (Chien, 2007). Likewise, early embryonic endothelial cell function depends on pulsatile blood flow (Burggren, 2013).

The relationship between CV development, morphogenesis, and biomechanical events is an area of active investigation (Clark and Hu, 1982; Le Noble et al., 2004; Lucitti et al., 2007). Mechanical, pharmacological, and genetic models that disrupt or eliminate blood flow have been used to demonstrate the requirement of hemodynamic forces for $\mathrm{CV}$ development (Hogers et al., 1999; Sedmera et al., 1999; Bartman et al., 2004; Vermot et al., 2009; Karunamuni et al., 2014). However, a paucity of quantitative morphometric and hemodynamic data limits our understanding of the phenotypic response. Molecular studies have identified some genes and signaling pathways involved in the hemodynamic response (Groenendijk et al., 2005; Yashiro et al., 2007; Egorova et al., 2011), but requires more research to delineate these relationships. We believe that a multidisciplinary approach is essential to incorporate all of the elements required to generate valid representations of the complex biology reflected in $\mathrm{CV}$ morphogenesis within adaptive and predictive computational models relevant to human CHD and to identify novel molecular regulatory threshold involved in development and remodeling (Pekkan and Keller, 2013).

Advanced methods of measuring cardiac function, improved imaging modalities enabling synchronus, high-resolution and three-dimensional (3D) live imaging, enhanced molecular techniques, and novel experimental interventions enable complementary, quantitative studies to link phenotypic growth, morphogenesis, and remodeling events with hemodynamic forces and fundamental biologic mechanisms. This review presents an overview of approaches to study hemodynamics and CV morphogenesis in the embryo and how they have contributed to our current understanding of developmental CV biomechanics. The development of computational models to investigate higher-order flow characteristics and mechanical loading is also addressed. Finally, the outlook for future research is discussed.

\section{IMAGING TECHNIOUES}

Classical studies of embryonic CV morphology were performed under microscopic observation and through thin tissue sections, creating several monographs on the subject (Patten, 1920; Hughes, 1934; Romanoff, 1960; Theiler, 1972). In recent years, serial tissue sections have been combined with in situ hybridization to create 3D reconstructions of the embryonic chick heart with segmented tissue structures (Van Den Berg and Moorman, 2011). Scanning electron microscopy (SEM) creates 3D surface renderings of the heart and vasculature, aiding in describing events such as cardiac looping (Manner, 2009). While tissue sections and SEM are useful for these descriptive studies, quantitative morphometry is limited due to the fixation processes. Recently, episcopic fluorescence image capture (EFIC) has been combined with cryo-embedding to obtain 3D geometries of the fetal mouse with minimal tissue distortion, allowing some quantitative analysis (Yap et al., 2014). These ex vivo approaches, wherein the embryo is fixed and removed from its developmental environment, are useful for understanding overall anatomy, but cannot provide information on dynamic biomechanical events. In the next sections, we review in vivo techniques that allow imaging of live embryos. 
In vivo embryonic imaging has become widely used to understand embryonic CV morphogenesis both qualitatively and quantitatively. Various modalities are currently employed, summarized in Table 2 (Gregg and Butcher, 2012). The fluorescent stereomicroscope remains a prominent tool for experiments and observation, including assessment of CV dimensions and tracking intracardiac flow patterns (Faber et al., 1974; Keller et al., 1990, 1996; Hogers et al., 1995; Al Naieb et al., 2012; Kowalski et al., 2014). Video microscopy has been used to measure ventricular epicardial surface-strain relations when combined with microspheres as fiducial markers (Tobita et al., 2002). However, these techniques are limited to tissue surfaces. Confocal microscopy offers high resolution, but is limited by shallow depth of view and primarily used in early stage embryos (Zamir et al., 2006; Yalcin et al., 2010). The small size and transparency of zebrafish can overcome some of these limitations, and transgenic zebrafish models have been combined with live confocal microscopy to analyze cardiac and blood flow dynamics (Forouhar et al., 2006; Corti et al., 2011). Multi-photon microscopy (MPM) combined with long working distance stereomicroscopy offers greater imaging depth than traditional confocal and provides 3D timelapse microstructural images. Multi-photon 2nd harmonic autofluorescence collagen and elastin in vivo imaging protocols are currently being used to complement standard microstructural immunohistochemistry (Robertson et al., 2012).

Micro-computed tomography (micro-CT) offers the greatest theoretical resolution and has been widely used to obtain $3 \mathrm{D}$ geometries of fixed tissues through contrast agents or polymeric casting of vascular structures (Butcher et al., 2007b; Kim et al., 2011; Wong et al., 2012). In vivo imaging is possible with micro-CT, but has been limited to date (Henning et al., 2011). Magnetic resonance microscopy (MRM) is another emerging high-resolution, in vivo modality (Bain et al., 2007; Holmes et al., 2009). Both micro-CT and MRM provide opportunity for quantitative morphometric analysis.

Ultrasound imaging of the mouse embryo was initially reported in 1995 by Turnbull et al. using an ultrasound backscatter microscope to study the embryonic brain in utero between embryo days 9.5 and 11.5 at a resolution of 50 microns (Turnbull et al., 1995). The following year, Gui et al. published the first application of ultrasound to quantify cardiac function in the normal and abnormal mouse embryonic heart (Gui et al., 1996; Zhou et al., 2003). This technology became incorporated into multiple paradigms to screen for congenital defects in mutagenesis screens for congenital heart defects (Yu et al., 2004) and to quantify changes in embryonic $\mathrm{CV}$ function in response to

Table 2 | Comparison of in vivo imaging modalities.

\begin{tabular}{lcc}
\hline & Resolution $(\boldsymbol{\mu} \mathbf{m})$ & Depth of Field $(\mathbf{m m})$ \\
\hline Confocal & 1 & 0.2 \\
MPM & 1 & 2 \\
micro-CT & $1-25$ & 80 \\
MRM & 30 & 100 \\
High frequency ultrasound & 30 & 35 \\
OCT & 4 & 2
\end{tabular}

maternal environmental factors (hypoxia, Furukawa et al., 2007; lithium, Chen et al., 2008; caffeine, Momoi et al., 2008) and in response to altered genes critical to cardiac morphogenesis (Zhou et al., 2005).

In recent years, optical coherence tomography (OCT) has emerged as a preferred method for live imaging of the chick embryo (Yelbuz et al., 2002; Davis et al., 2008; Manner et al., 2008). OCT is non-invasive and the $4 \mu \mathrm{m}$ resolution is on the scale of micro-CT and greater than MRM (Yelbuz et al., 2002; Zhang et al., 2003; Kim et al., 2011). The scan rate of OCT is near 100 2D frames per second, sufficient to capture the dynamic cardiac cycle of chick embryos. OCT is limited by light scattering in embryonic tissue and has a depth of view of $1-2 \mathrm{~mm}$. The speed and non-invasive aspects of confocal microscopy and OCT have been leveraged to enable long-term, time-lapse imaging (Kamei and Weinstein, 2005; El-Ghali et al., 2010; Kulesa et al., 2010; Happel et al., 2011).

Despite these in vivo techniques, quantitative analysis of $\mathrm{CV}$ morphogenesis remains lacking. To understand the influence of biomechanical cues such as hemodynamic force, a greater knowledge-base of CV morphometry is required. In particular, comparisons between normal and experimentally perturbed CV morphogenesis cannot occur without quantitative phenotypic data. Long-term imaging techniques offer a unique approach, as they provide spatially and temporally resolved data, which can be quantitatively analyzed. Previous studies using micro-CT (Henning et al., 2011) and MRM (Bain et al., 2007; Holmes et al., 2009) have followed single embryos over a period of days to quantify organ volume growth and changes in cardiac function. Embryos were imaged at set intervals and returned to the incubator in the interim. The imaging environment varied among the different studies from room air (Bain et al., 2007) to full temperature and humidity control (Henning et al., 2011). Longterm, time-lapse imaging of live embryos, where a single embryo is kept within an imaging platform and followed continuously for a period of hours or days, has been achieved by constructing controllable chambers to maintain physiologic environmental conditions (Orhan et al., 2007; Gargesha et al., 2009; Kulesa et al., 2010; Ma et al., 2010; Happel et al., 2011; Al Naieb et al., 2012). The chick embryo has been studied using long-term, time-lapse techniques combined with both confocal microscopy to track moving cell populations over a period of more than $26 \mathrm{~h}$, in 1.5 min intervals (El-Ghali et al., 2010; Kulesa et al., 2010) and OCT to measure cardiac function over a $6 \mathrm{~h}$ period, in $60 \mathrm{~min}$ intervals (Happel et al., 2011). A confocal system has been developed for long-term, time-lapse imaging of the zebrafish embryo as well, capable of a 5 day period, in $10 \mathrm{~min}$ intervals (Kamei and Weinstein, 2005). A challenge of these continuous techniques is maintaining the embryo in an exposed and stationary state to facilitate imaging. Shell-less or ex ovo culture systems are often used in long-term studies of chick embryos (Teddy et al., 2005; El-Ghali et al., 2010; Happel et al., 2011), though an in ovo confocal protocol has been proposed (Kulesa et al., 2010). In the case of zebrafish embryos, immobile mutants or tricaine anesthetized embryos are used (Kamei and Weinstein, 2005). The effects of these conditions on embryonic development should be addressed when designing the experiment and analyzing the 
data. For example, shell-less culture of chick embryos has been associated with changes in heart rate and developmental delay compared to in ovo embryos (Auerbach et al., 1974; Yelbuz et al., 2000).

\section{CARDIAC FUNCTION MEASUREMENTS INTRACARDIAC FLOW PATTERNS}

Early investigations of the hemodynamic influence on CV development focused on intracardiac flow patterns. Flow patterns in the chick embryo were described through observation of the erythrocytes, and led to a widely perceived notion that a spiraling pattern of flow streams determined cardiac septation (Bremer, 1932; Jaffee, 1965). Dye injections and improved microscopy techniques of later researchers disproved these conclusions, but maintained that separate flow streams exist in the embryonic heart (Yoshida et al., 1983; Hogers et al., 1995). Intracardiac flow patterns depend on both the site of origin and embryonic stage (Rychter and Lemez, 1965; Yoshida et al., 1983; Hogers et al., 1995). Although these patterns do not predict the eventual location and shape of the septa, their disruption does result in a variety of cardiovascular defects including ventricular septal defects, bicuspid aortic valve, and anomalies of the great arteries (Hogers et al., 1999), suggesting that these flow streams provide some environmental cues for cardiac morphogenesis.

\section{BLOOD FLOW VELOCITY}

As embryonic development proceeds, cardiac physiology changes rapidly. Measurements of cardiac function are primarily performed in chick embryos, as they are amenable to instrumentation. For decades, pulsed-Doppler ultrasound has been the standard technique for velocity, stroke volume, and cardiac output measurements in the embryo ( $\mathrm{Hu}$ and Clark, 1989; Broekhuizen et al., 1993; Phoon et al., 2000; Ursem et al., 2001). Doppler ultrasound measures the phase shift between two consecutive pulses to determine velocity of moving particles, such as red blood cells. The Doppler shift is measured in the direction of the ultrasound beam, and is therefore a $1 \mathrm{D}$ measurement (Zheng et al., 2006). The angle between the ultrasound beam and vessel centerline, the Doppler angle, is used to compute velocity. Measurement of the vessel diameter is combined with the velocity time integral (over one cardiac cycle) to compute stroke volume. Frequency analysis of the velocity waveform can be used to compute heart rate. Recent studies have used highfrequency $(43-55 \mathrm{MHz})$ ultrasound, referred to as ultrasound biomicroscopy, due to the greater spatial resolution $(30 \mu \mathrm{m})$. This increased spatial resolution enables measurement of chamber specific cardiac flows as well as velocity measurements in small vessels such as the aortic arches (Table 3; Phoon et al., 2000; Zhou et al., 2003; Butcher et al., 2007a; Hu et al., 2009; Oosterbaan et al., 2009).

OCT, another echo-based imaging modality, can produce higher resolution Doppler velocity measurements, though it has less depth of view. OCT uses low-coherence infrared light source and relies on interferometry to determine the location of back-reflected light. OCT measures a $1 \mathrm{D}$ velocity component, which must be combined with the angle between the beam and vessel centerline in order to obtain the true velocity. The
Table 3 | Peak velocity measurements in normal embryos.

\begin{tabular}{|c|c|c|c|c|c|}
\hline Animal & Stage & Location & $\begin{array}{c}\text { Peak } \\
\text { velocity } \\
\text { (cm/s) }\end{array}$ & Technique & References \\
\hline Chick & $\mathrm{HH} 25$ & $\begin{array}{l}\text { Atrioventricular } \\
\text { canal }\end{array}$ & 17.1 & Ultrasound & $\begin{array}{l}\text { Butcher } \\
\text { et al., 2007a }\end{array}$ \\
\hline \multirow[t]{2}{*}{ Chick } & $\mathrm{HH} 21$ & Inflow tract & 5.0 & Ultrasound & $\begin{array}{l}\text { Oosterbaan } \\
\text { et al., } 2009\end{array}$ \\
\hline & & Outflow tract & 6.1 & & \\
\hline \multirow[t]{2}{*}{ Mouse } & day 14.5 & Mitral & 34.4 & Ultrasound & $\begin{array}{l}\text { Zhou et al., } \\
2003\end{array}$ \\
\hline & & Tricuspid & 33.4 & & \\
\hline Chick & $\mathrm{HH} 18$ & Outflow tract & 7.8 & Doppler-OCT & $\begin{array}{l}\text { Rugonyi } \\
\text { et al., } 2008\end{array}$ \\
\hline Mouse & day 9.5 & Dorsal aorta & 0.8 & Doppler-OCT & $\begin{array}{l}\text { Larina et al., } \\
2008\end{array}$ \\
\hline \multirow[t]{2}{*}{ Quail } & $\mathrm{HH} 14$ & Inflow tract & 2.62 & Doppler-OCT & $\begin{array}{l}\text { Jenkins } \\
\text { et al., } 2010\end{array}$ \\
\hline & & Outflow tract & 5.1 & & \\
\hline Chick & $\mathrm{HH} 17$ & Vitelline & 0.32 & Doppler-OCT & $\begin{array}{l}\text { Davis et al., } \\
2009\end{array}$ \\
\hline Chick & $\mathrm{HH} 15$ & Ventricle & 2.6 & PIV & $\begin{array}{l}\text { Vennemann } \\
\text { et al., } 2006\end{array}$ \\
\hline Chick & $\mathrm{HH} 18$ & Vitelline & 0.08 & PIV & $\begin{array}{l}\text { Poelma } \\
\text { et al., } 2008\end{array}$ \\
\hline Chick & $\mathrm{HH} 18$ & Vitelline & 0.1 & OCT-PIV & $\begin{array}{l}\text { Chen et al., } \\
2012\end{array}$ \\
\hline
\end{tabular}

maximum velocities measured with Doppler-OCT are limited by the scanning frequency of the OCT system, however phase unwrapping algorithms can be used to correct for slower scan rates (Davis et al., 2009). The resolution of OCT is such that it can measure velocity profiles, which is advantageous for calculating hemodynamic loading.

Apart from Doppler methods, micro particle image velocimetry ( $\mu$ PIV) has been used to measure blood flow velocities in chick and zebrafish embryos. $\mu$ PIV uses cross-correlation between two consecutive images to calculate local displacements. In chick embryos, erythrocytes or injected fluorescent microspheres have been used as the seeding particles (Poelma et al., 2012). At high magnification, however, the use of red blood cells as tracer particles significantly underestimated the flow velocity (Poelma et al., 2012). Zebrafish experiments required transgenic embryos expressing green and red fluorescent proteins in endothelial and red blood cells, respectively (Chen et al., 2011). A high-speed camera integrated with a microscope or high speed scanning confocal are typically used to capture the source images. Unlike the previous Doppler methods, $\mu$ PIV generates a field of $2 \mathrm{D}$ velocity vectors, which can identify flow structures such as vortices. OCT can be used as the imaging source for $\mu \mathrm{PIV}$, as its speed and spatial resolution is sufficient to capture moving red blood cells. This technique, OCT- $\mu$ PIV, has been applied to chick embryo vitelline vessels (Chen et al., 2012).

Cardiac output increases exponentially during embryonic development (Figure 1). Dorsal aortic flow, measured with 20 $\mathrm{MHz}$ directional pulsed Doppler ultrasound, is typically given 
as cardiac output, though it ignores cerebral perfusion (Clark and Hu, 1982; Hu and Clark, 1989; Broekhuizen et al., 1993, 1999; Yoshigi et al., 2000; Ursem et al., 2001; Lucitti et al., 2005, 2006). While this exponential rise in cardiac output is consistently observed, the reported values vary among researchers and depend upon reporting instantaneous peak or mean values (Figure 1). This variation may be due to measurement technique and experimental conditions. Using ultrasound biomicroscopy it is possible to investigate ventricular filling patterns. Similar to the mature heart, ventricular filling is biphasic in the embryo (Zhou et al., 2003; Butcher et al., 2007a; Oosterbaan et al., 2009). Peak velocity during passive ventricular filling increases exponentially during mouse embryonic development, while peak velocity during active filling changes logarithmically (Ishiwata et al., 2003; Zhou et al., 2003). Interestingly, in early stage chick embryos (HH17-23), the peak velocity during passive ventricular filling decreased (Butcher et al., 2007a; Oosterbaan et al., 2009). This trend suggests that maturation of myocardial relaxation occurs differently in chick and mouse embryos. Doppler ultrasound has been used to measure pulse wave velocity in the chick dorsal aorta via a dual-channel velocimeter. Pulse wave velocities ranged from 60 to $100 \mathrm{~cm} / \mathrm{s}$ in embryos from HH21 to 27 (Lucitti et al., 2006).

Velocity measurements obtained using Doppler-OCT are similar to ultrasound (Table 3). Experiments with mouse and chick embryos demonstrate the utility of Doppler-OCT to obtain blood flow velocities at various locations, including the outflow tract and dorsal aorta (Larina et al., 2008; Rugonyi et al., 2008; Jenkins et al., 2010). $\mu$ PIV analysis of flow within the HH15 chick ventricle revealed a laminar regime (peak Reynolds number 0.5 ), but

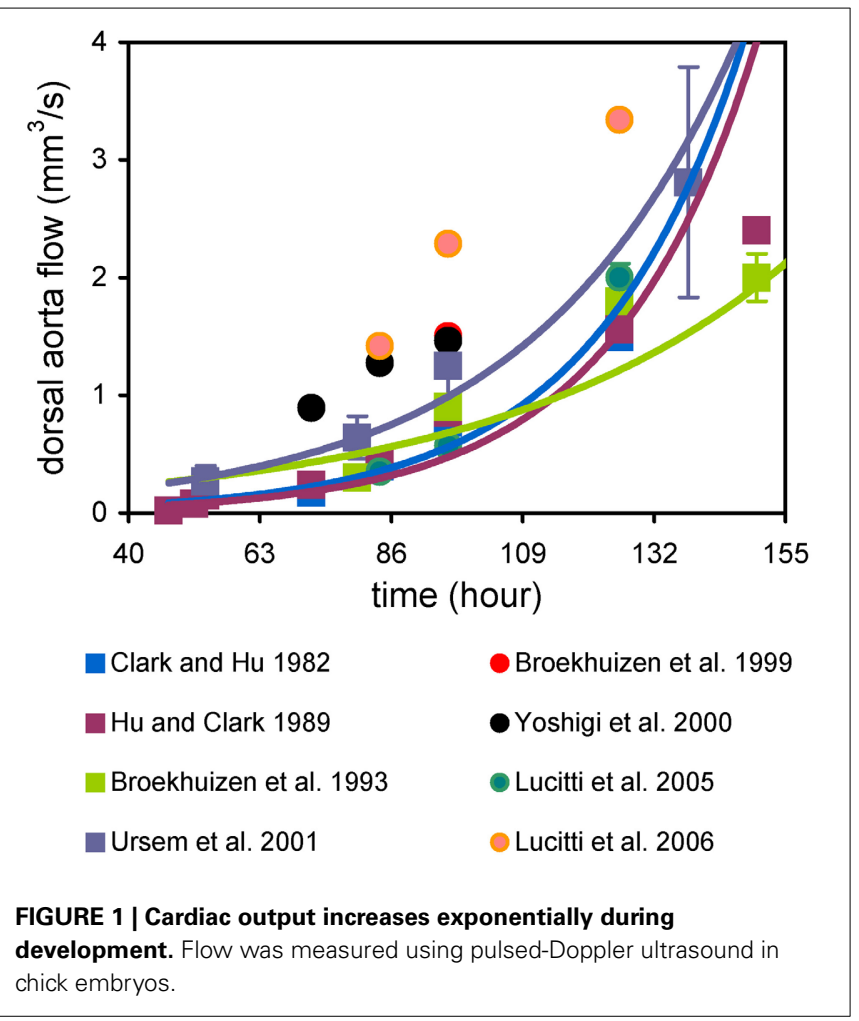

an asymmetric velocity profile skewed toward the inner curvature of the heart (Vennemann et al., 2006). This skewed profile indicated a region of increased WSS at the inner curvature, consistent with WSS maps computed from $\mu$ PIV and OCT data, as described below. Additional $\mu$ PIV studies showed that blood flow within the embryonic cardiovascular system is laminar and quasi-steady, with low Reynolds (Re) and Womersley (Wo) numbers (Figure 2; Poelma et al., 2008). In the chick embryo dorsal aorta, Re and Wo range between 0.1 and 9 and 0.5 and 3, respectively, between HH12 and 36, compared to values of Re 1000 and Wo 40 in the mature human aorta. Computing Re and Wo numbers requires blood viscosity, which can differ significantly between embryonic and mature blood. In mature mammals, blood exhibits nonNewtonian behavior, in which the apparent viscosity decreases nonlinearly with increasing shear rates (Fung, 1997). This nonNewtonian rheology is primarily due to the presence of red blood cells, which are biconcave and deformable. Embryonic red blood cells, however, are spherical and make up a smaller percentage of the blood volume (Rychter et al., 1955). Rheological studies of HH24-34 chick embryonic blood revealed that hematocrit increases linearly, however the embryonic blood behaved as a Newtonian fluid throughout the investigated stages (Al-Roubaie et al., 2011). Hematocrit was also shown to be a good predictor of blood viscosity in the chick embryo.

An advantage of both OCT and $\mu$ PIV techniques is the capability to obtain a velocity profile. These methods can therefore be used to compute the important biomechanical factor, WSS. WSS is defined as the shear rate (velocity gradient at the wall) multiplied by blood viscosity. For straight vessels, it is simple to compute the shear rate. However, for curved vessels, the vector normal to the wall must be obtained. $\mu$ PIV methods performed in 2D can compute the normal vector from the microscopy image (Vennemann et al., 2006). OCT has the

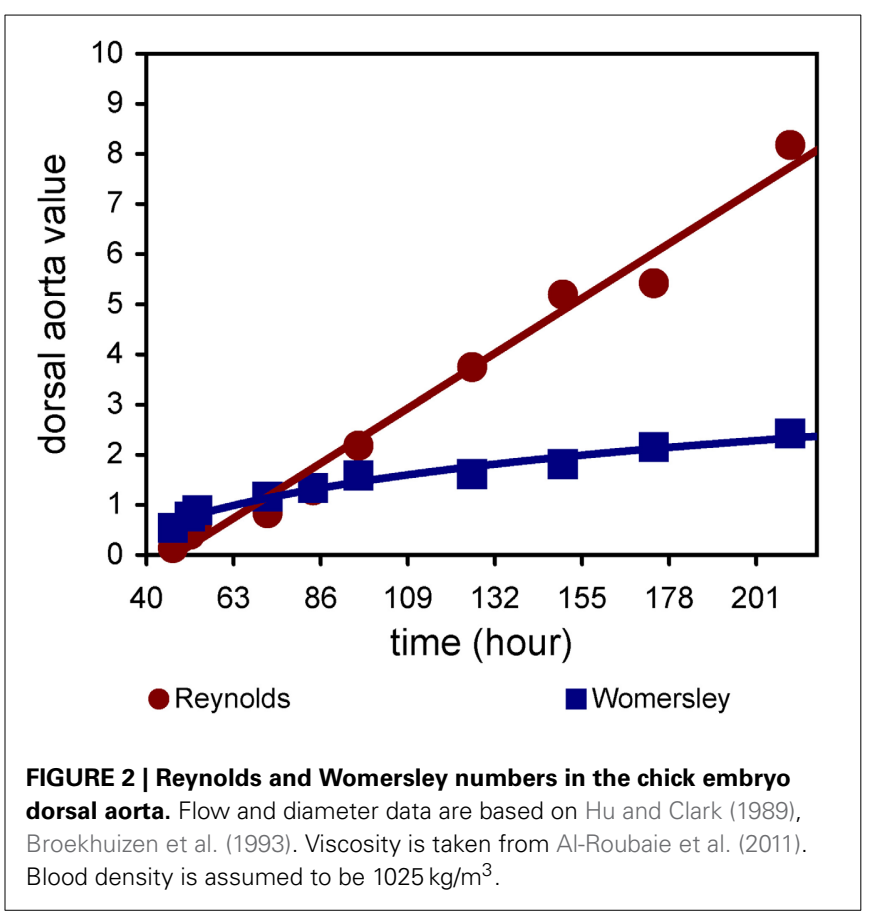


advantage of simultaneously acquiring structural and velocity data. Reconstructing the embryonic heart or vessel in $3 \mathrm{D}$ can give the wall normal vector, thus enabling WSS calculation. This approach has been used to obtain WSS levels in the early heart tube and vitelline veins (Davis et al., 2009; Jenkins et al., 2010; Peterson et al., 2012). Note that 4D reconstructions must be applied for the beating heart tube. A study using scanning $\mu$ PIV to acquire a $3 \mathrm{D}$ flow field found WSS levels between 1 and $3 \mathrm{~Pa}$ in the outflow tract of an HH17 chick embryo (Poelma et al., 2010). An OCT-based study of the HH14 quail heart showed a region of high WSS $(8 \mathrm{~Pa})$ at the inner curvature of the outflow tract compared to other areas of the heart (2-3 Pa) (Peterson et al., 2012). These experimentally measured WSS values agree with computational modeling approaches (Table 4). OCT and $\mu$ PIV techniques provide spatially resolved WSS maps, which can be coupled with local growth maps to investigate relationships between WSS and CV growth.

\section{PRESSURE, RESISTANCE, AND IMPEDANCE}

Intraventricular and intravascular pressure measurements in the embryo are performed with a servo-null transducer and drawn micropipette electrode (Falchuk and Berliner, 1971; Heineman and Grayson, 1985). End-diastolic and peak systolic ventricular pressures in chick and mouse embryos increase exponentially with developmental age, though peak systolic pressure increases more rapidly (Figure 3; Clark et al., 1986; Hu and Clark, 1989; Ishiwata et al., 2003). Thus, the pulse pressure

Table 4 | Peak WSS values in normal embryos.

\begin{tabular}{|c|c|c|c|c|c|}
\hline Animal & Stage & Location & $\begin{array}{l}\text { Peak } \\
\text { WSS } \\
(\mathrm{Pa})\end{array}$ & Technique & References \\
\hline Quail & $\mathrm{HH} 14$ & Heart & 8.40 & OCT & $\begin{array}{l}\text { Jenkins et al., } \\
2010\end{array}$ \\
\hline Quail & $\mathrm{HH} 14$ & Heart & 8.10 & $\mathrm{OCT}$ & $\begin{array}{l}\text { Peterson et al., } \\
2012\end{array}$ \\
\hline Chick & $\mathrm{HH} 17$ & Outflow tract & 3.00 & PIV & $\begin{array}{l}\text { Poelma et al., } \\
2010\end{array}$ \\
\hline Chick & $\begin{array}{l}\mathrm{HH} 17 \\
\mathrm{HH} 23 \\
\mathrm{HH} 27 \\
\mathrm{HH} 30\end{array}$ & $\begin{array}{l}\text { Atrioventricular } \\
\text { canal }\end{array}$ & $\begin{array}{r}1.93 \\
7.83 \\
25.01 \\
28.72\end{array}$ & CFD & $\begin{array}{l}\text { Yalcin et al., } \\
2011\end{array}$ \\
\hline Chick & $\begin{array}{l}\mathrm{HH} 18 \\
\mathrm{HH} 24\end{array}$ & Aortic arches & $\begin{array}{l}5.47 \\
9.56\end{array}$ & CFD & $\begin{array}{l}\text { Wang et al., } \\
2009\end{array}$ \\
\hline Chick & $\begin{array}{l}\mathrm{HH} 16 \\
\mathrm{HH} 23 \\
\mathrm{HH} 27 \\
\mathrm{HH} 30\end{array}$ & Outflow tract & $\begin{array}{r}1.82 \\
5.82 \\
23.61 \\
53.61\end{array}$ & CFD & $\begin{array}{l}\text { Bharadwaj } \\
\text { et al., } 2012\end{array}$ \\
\hline Chick & $\mathrm{HH} 18$ & Outflow tract & 6.00 & CFD & Liu et al., 2012 \\
\hline Chick & $\mathrm{HH} 17$ & Outflow tract & 3.20 & PIV & $\begin{array}{l}\text { Poelma et al., } \\
2010\end{array}$ \\
\hline
\end{tabular}

between end-diastole and peak systole increases over development. Ventricular pressure waveforms in the embryo are similar to the mature heart, which suggests that endocardial cushions function as heart valves. Simultaneous atrial and ventricular pressure measurements in the chick embryo examined the atrioventricular $(\mathrm{AV})$ pressure gradient, which remained approximately $0.2 \mathrm{mmHg}$ from $\mathrm{HH} 16$ to 21 , but increased sharply to $0.6 \mathrm{~mm}$ by HH27 (Hu and Keller, 1995). The sharp increase may be related to septation of the atrium and AV canal. This study also found that atrial pressure exceeds ventricular pressure throughout ventricular filling ( $\mathrm{Hu}$ and Keller, 1995) suggesting that the developing AV cushions have some passive resistance during diastole. A pressure gradient also exists between the embryonic ventricle and descending aorta, consistent with a combined resistance of the outlet cushions and the aortic arches. Pressure measurements of vitelline arteries in chick embryos revealed a linear increase (Clark and Hu, 1982; Hu and Clark, 1989). The linear increase in arterial pressure coupled with exponential rise in cardiac output produces a geometric decrease in vascular resistance (Table 5; Hu and Clark, 1989; Lucitti et al., 2005). These trends occur concurrently with increasing ventricular size and weight, myofiber organization, and increased ventricular trabeculation (Sedmera et al., 1999, 2000; Tobita et al., 2005; Baker et al., 2008). In section Hemodynamic Intervention Models of this review, we discuss how experiments that perturb embryonic blood flow demonstrate that these hemodynamic and structural changes are linked.

Pressure measurements have been combined with video microscopy to analyze pressure-volume relationships in the chick embryo. Initially, pressure-area loops were used, where epicardial ventricular cross-section area was measured from video recordings. These pressure-area loops resembled mature

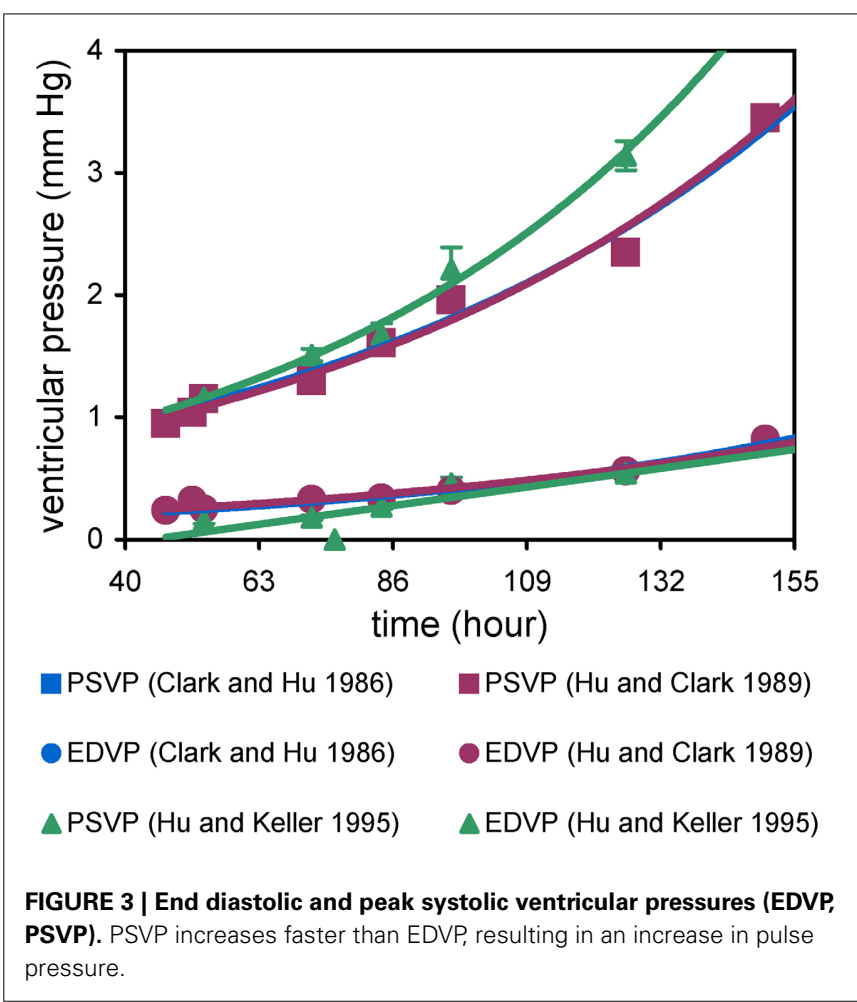


Table 5 | Vascular hemodynamic properties of the normal chick embryo.

\begin{tabular}{lcccc}
\hline Stage & $\begin{array}{c}\text { Vascular } \\
\text { resistance } \\
\left(\mathbf{m m H g} / \mathbf{m m}^{\mathbf{3}} \mathbf{/ s}\right)\end{array}$ & $\begin{array}{c}\text { Cardiac } \\
\text { work } \\
\text { (n) } \mathbf{~}\end{array}$ & $\begin{array}{c}\text { Systolic } \\
\text { pressure } \\
(\mathbf{m m H g})\end{array}$ & $\begin{array}{c}\text { Total } \\
\text { hydraulic power } \\
\text { (nW) }\end{array}$ \\
\hline $\mathrm{HH} 18$ & 2.95 & 9.3 & 1.14 & 48 \\
$\mathrm{HH} 21$ & 2.05 & 20.0 & 1.48 & 108 \\
$\mathrm{HH} 24$ & 1.21 & 41.3 & 1.82 & 296 \\
$\mathrm{HH} 27$ & 0.83 & 89.3 & 2.51 & 1054 \\
$\mathrm{HH} 29$ & 0.63 & 138.9 & 3.04 & 2203 \\
\hline
\end{tabular}

References: Hu and Clark, 1989; Zahka et al., 1989.

pressure-volume loops, with clearly observed diastolic filling, isometric contraction, ejection, and isometric relaxation phases (Keller et al., 1991). Isometric contraction times increased linearly from $\mathrm{HH} 16$ to $\mathrm{HH} 24$ while isometric relaxation times remained similar. This technique was expanded to generate pressure-volume loops by using an ellipsoid geometry model to estimate ventricular volume based on area (Stekelenburg-De Vos et al., 2005). These pressure-volume loops have been used to compute contractility and compliance properties of the embryonic ventricle. Additionally, the presence of isometric contraction and relaxation provide further evidence that the endocardial cushions function as valves.

Simultaneous velocity and pressure measurements at the dorsal aorta allow for analysis of impedance and hydraulic power. In the chick embryo, the first, second, and third impedance moduli all decreased from HH18 to 29 (Zahka et al., 1989). This decrease is likely due to growth and remodeling of the dorsal aorta and vascular bed. Total hydraulic power of the chick embryo CV increased 50-fold from 48 to $2600 \mathrm{nW}$ between HH18 and 29 (Table 5), while the proportion of hydraulic power due to pulsatile flow increased from 28 to 65\% (Zahka et al., 1989). Remarkably, the embryonic vascular bed can be accurately represented by a 3 element Windkessel model, similar to the mature circulation (Yoshigi et al., 2000) and the embryonic vasculature rapidly adjusts impedance to loading conditions, similar to the ability of the ventricle to rapidly adjust to changes in preload and afterload.

Structural remodeling of large arteries and veins, from thin mesenchymal sheaths to organized, multi-layer lamellae of circumferentially oriented smooth muscle cells and extracellular matrix components such as elastin and collagen occurs along with the exponential rises in blood pressure and flow (Deruiter et al., 1993; Hungerford et al., 1996; Waldo et al., 1996; Majesky et al., 2011). Shear stress and cyclic transmural stress and strain are important biomechanical factors regulating microstructural remodeling; in mouse embryos with impaired cardiac contractility, blood vessels appeared disorganized with separated endodermal and mesodermal layers (Huang et al., 2003; May et al., 2004). Large arteries near the heart have high elastin content, which allows them to elastically deform under high pressure, creating a windkessel effect necessary to maintain blood flow at the physiologic pressure range. In mouse embryos lacking elastin, deformation of the aortic wall, measured with M-mode ultrasound, was 3 times less vs. controls at day 18 (Wagenseil et al., 2009). The production of extracellular matrix components is indicative of smooth muscle maturation, and the time-course of extracellular matrix gene expression follows hemodynamic trends during embryonic and postnatal development: expression is high during rapid increases in pressure and flow and minimal once a stable hemodynamic state is achieved (Wagenseil and Mecham, 2009). Additional discussion of the development and remodeling large arteries can be found in previously published reviews (Ribatti, 2006; Cheng and Wagenseil, 2012; Seidelmann et al., 2014).

\section{PLACENTAL CIRCULATION AND MATERNAL STRESS}

The exchange of nutrients, gas, water, and metabolic waste during embryonic and fetal life is carried out through the extraembryonic umbilical circulation. In placental mammals, the umbilical circulation connects with the placenta, which is also connected to the mother via the uterine circulation, and exchange between fetal and maternal blood occurs across various plasma membranes (Desforges and Sibley, 2010). Other amniotes such as birds and reptiles rely on the vitelline circulation to receive nutrients from the yolk and the allantois for gas and nitrogenous waste exchange. These external circulation pathways are eliminated after birth, but have important roles in shaping the hemodynamic environment of the embryo. Umbilical blood flow increases exponentially over gestation, following both fetal growth rates and increases in cardiac output (Rudolph and Heymann, 1970; Reynolds and Redmer, 1995). Throughout the last half of gestation in humans, umbilical blood velocity increases and resistance decreases (Gadelha Da Costa et al., 2005). This increased blood flow allows for greater placental transport capacity to support the geometric increase in fetal oxygen demand, for example a 16-fold increase in oxygen uptake in the bovine fetus from mid-to-late gestation (Reynolds et al., 1986).

Sheep models of compromised pregnancy, including nutrient deprivation, nutrient excess, environmental heat stress, and hypoxic stress all lead to low placental weight and decreased uterine and umbilical blood flow (Krebs et al., 1997; Regnault et al., 2003; Wallace et al., 2005), similar to human conditions. Fetal oxygen and nutrient uptakes are reduced in these models. In humans, restricted uterine and umbilical blood flows resulted in fetal hypoxia, hypoglycemia, and asymmetric organ growth (Pardi et al., 1993; Ferrazzi et al., 2000). Placental insufficiency is associated with the majority of intrauterine growth restriction, with etiologies including fetal genetic diseases or congenital malformations, maternal hypertensive disorders causing reduced uteroplacental flow, decreased oxygen carrying capacity of the mother, and malnourishment (Hendrix and Berghella, 2008). These conditions lead to decreased systolic and diastolic cardiac function in the fetus as well as free wall hypertrophy and increased coronary blood flow (Bahtiyar and Copel, 2008). Thus, maternal stresses causing impaired uterine blood flow and compromised placental function and circulation directly affect fetal growth (Reynolds et al., 2005, 2010). Removal of the umbilical circulation after birth by cord clamping is additionally indicated as a potential source of hemodynamic disruption, as it can limit transfer of placental blood and prostaglandins to the neonate (Sommers 
et al., 2012; Bhatt et al., 2013; Hutchon, 2013; Raju, 2013; Yigit et al., in review).

\section{COMPUTATIONAL MODELING APPROACHES}

Development of computational models is vital to investigating the biomechanics of $\mathrm{CV}$ development. Models are used to calculate data that cannot be measured experimentally and enable incremental studies where a single parameter can be methodically altered. Aspects of the embryonic CV have been modeled using a variety of methods, including computational fluid dynamics (CFD), continuum solid mechanics, and lumped parameter models. Experimental data is required to train and test the results of computational models and is often needed for initial inputs. Insights gained from modeling can, in turn, inspire new experiments. Thus, experiments and models complement each other and are both needed to study embryonic CV development.

CFD is widely used to analyze hemodynamics at a higher level than Doppler velocimetry or $\mu$ PIV can provide. Doppler techniques are not suited for complex flow fields and $\mu$ PIV requires vessels that are accessible and not obscured. CFD models overcome these limitations by providing 3D data. Model geometries are often obtained from imaging techniques described in Section Introduction. Pressure and velocity measurements are used to set realistic boundary conditions. Depending on the model objectives, blood flow can be at he mean steady-state or pulsatile. CFD models of flow through the AV canal of chick embryos at different stages of development demonstrated that WSS increases monotonically and is higher on the left side of the heart (Table 4; Yalcin et al., 2011; Bharadwaj et al., 2012). A CFD model of the HH18 chick embryo outflow tract that incorporates wall motion was developed based on 4D OCT measurements and revealed that WSS is highest at the outer curvature and on the endocardial cushions (Liu et al., 2011). Models of blood flow through the chick embryo aortic arches quantified flow patterns and cardiac output distribution at HH18, 21, and 24 (Figure 4; Wang et al., 2009; Kowalski et al., 2013). These models were coupled with experimental measurements of aortic arch diameter and revealed a correlation between asymmetric flow distributions and asymmetric growth. Further, WSS was shown to become elevated at the intermediate, transitional stage $\mathrm{HH} 21$ and then return to previous levels by $\mathrm{HH} 24$. Each of these models uncovered hemodynamic features that could not be captured by experiment alone. By combining experimental and modeling techniques, new insights are gained into the biomechanical influence on $\mathrm{CV}$ growth and morphogenesis.

Computational models that recapitulate or predict embryonic CV growth are emerging and have been developed with some success. A common approach is to use a stress-based growth law that assumes a hypothetical homeostatic stress state. A mechanistic growth field is generated in order to reach this equilibrium state. This approach was used to develop a model of growth and remodeling of the heart from its first beat to maturity (Taber and Chabert, 2002). The model incorporated myocardial trabeculation and compaction by applying temporal changes to material coefficients. When applying a radial cut, the opening angle predicted in the model agreed reasonably with experimental data. In a model of $\mathrm{AV}$ valve growth, fluid dynamics were incorporated into a stress-based model, where flow simulations occurred after growth integration in order to compute the new biomechanical load (Buskohl et al., 2012). This model showed that pressure distribution drove leaflet elongation while shear regulated structural remodeling. Aortic arch selection was modeled using a CFD-coupled optimization framework, where individual aortic arch diameters were varied to minimize total power and maximize diffusive capacity (Kowalski et al., 2012). The model predicted HH18 aortic arch diameters to within one standard deviation of experimental values. Further research will lead to predictive models that can be used to test the progression of CHD.

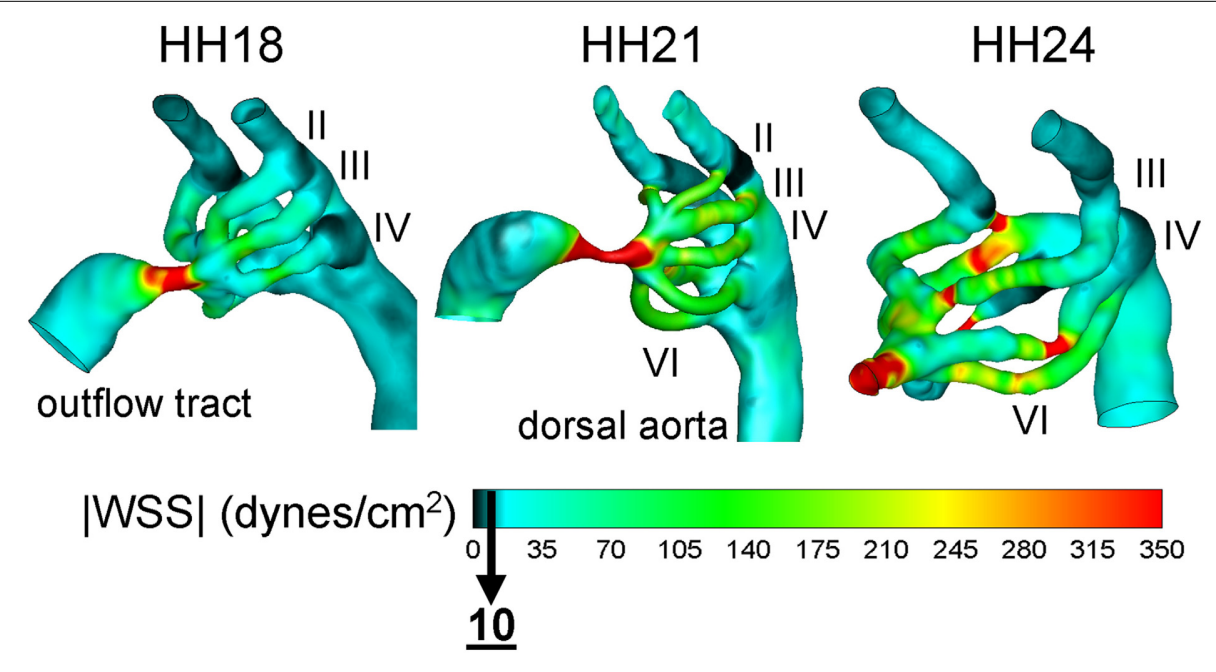

FIGURE 4 | Aortic arch peak flow wall shear stress (WSS) distribution for HH 18, 21, and 24 chick embryos. WSS is computed based on a CFD model. Aortic arches are viewed from a left oblique angle and numbered by roman numeral (II-VI). In order to display a broader range, a peak WSS of 350 dynes/cm2 is shown. Adapted from Wang et al. (2009), Kowalski et al. (2013). 


\section{HEMODYNAMIC INTERVENTION MODELS}

Early experiments performed by Rychter sought to disrupt blood flow by occluding various segments of the CV system through ligation or clipping (Rychter, 1962; Rychter and Lemez, 1965). Though primarily qualitative descriptions of the resulting morphological changes, these experiments provided direct evidence that hemodynamic disruptions generate CV defects. Currently, mechanical interventions, genetic mutations, and pharmacological manipulations are used in conjunction with the quantitative techniques described above to provide further insight into the biomechanical regulation of CV morphogenesis. The size and access of the chick embryo makes it an ideal model for surgical interventions, while genetic models are more commonly founded on mouse and zebrafish. The sections below describe a variety of interventions designed to perturb embryonic hemodynamics. These examples are not exhaustive, but provide background on some of the more commonly used approaches.

\section{VITELLINE VEIN LIGATION (VVL)}

Occlusion of a major vitelline vein by ligation or placement of a clip mimics reduced placental blood flow and is one of the most widely used interventions to modify blood flow. Performed on HH17 chick embryos, cardiac defects observed at HH36-45 included ventricular septal defects, AV canal defects, bicuspid aortic and quadricuspid pulmonary valves, interrupted aortic arch, double aortic arch, and hypoplastic pulmonary arteries (Hogers et al., 1999). VVL immediately disrupts intracardiac flow patterns, particularly at the AV canal and outflow tract (Hogers et al., 1999). Cardiac output, peak flow in the dorsal aorta, and heart rate all reduced immediately following right lateral VVL; heart rate and cardiac output returned to normal levels within $3 \mathrm{~h}$ (Stekelenburg-De Vos et al., 2003). After 1.5 days of chronic ligation, only peak acceleration in the dorsal aorta was reduced; dorsal aorta diameter, peak and mean velocity and flow, stroke volume and dorsal aorta pressure were normal (Broekhuizen et al., 1999). By 5.5 days after ligation, stroke volume and peak and mean dorsal aorta velocity and flow were increased, which also coincided with a ventricular septal defect in 6 out of 13 embryos (Broekhuizen et al., 1999). After placement of a clip on the right vitelline vein at $\mathrm{HH} 17$, analysis of pressure-volume loops at $\mathrm{HH} 21$ showed reduced contractility and compliance, which may indicate impaired myocardial development (Stekelenburg-De Vos et al., 2005).

These hemodynamic changes have been linked to altered expression of Kruppel-like factor 2 (KLF2), endothelin-1 (ET-1) and endothelial nitric oxide synthase (NOS-3) within the embryonic heart $1 \mathrm{~h}$ after right lateral VVL (Groenendijk et al., 2005). Increased KLF2 and NOS-3 expression was present at the narrowing of the AV canal, the junction between the AV canal and outflow tract cushions, and the upstream slope of the outflow tract, while KLF2 was decreased in downstream AV canal and the descending aorta. ET-1 was downregulated at the downstream slope of the AV canal and in the junction between the AV canal and outflow tract cushions and was increased in the dorsal aorta. Analysis of blood flow in the outflow tract using $\mu$ PIV showed that the WSS distribution at peak systole increased after VVL (Egorova et al., 2011). The expression patterns in the outflow tract (KLF2 and NOS-3 upregulated) are consistent with increased WSS. Additionally, TGF $\beta /$ ALK5 signaling was increased in endothelial cells lining the outflow tract cushions (Egorova et al., 2011). Further studies on ex vivo cultures of embryonic mouse endothelial cells demonstrated shear-mediated ALK5 signaling (Egorova et al., 2011). These VVL models provide some of the strongest evidence for biomechanical regulation of CV development, especially the role of WSS in modifying gene expression and signaling.

\section{OUTFLOW TRACT BANDING (OTB)}

Increasing afterload by tightening a suture around the embryonic outflow tract has generated valuable insight into the role of ventricular pressure on myocardial remodeling (Clark et al., 1989). OTB accelerates trabecular remodeling and myocardial compaction, resulting in a thickened compact layer (Sedmera et al., 1999). Additionally, myofiber organization is accelerated in OTB chick embryos (Tobita et al., 2005). Ventricular septal defects with either double outlet right ventricle or persistent truncus arteriosus occur after OTB as well as valvular anomalies (Sedmera et al., 1999). Mechanical testing of left ventricle tissue sections showed significantly stiffer stress-stain relations 2 days after OTB (Miller et al., 2003). Ventricular stiffening was also observed in pressure-inflation tests of excised hearts after OTB, which further showed that the right ventricle normalized end-diastolic strain rather than stress while the left ventricle normalized both end-diastolic strain and stress (Tobita et al., 2002). Structural and Doppler OCT measurements of HH18 OTB chick embryos demonstrated restricted outflow tract motion and increased blood velocity $(110 \mathrm{~mm} / \mathrm{s}$ OTB vs. $78 \mathrm{~mm} / \mathrm{s}$ normal peak velocity) (Rugonyi et al., 2008).

\section{LEFT ATRIAL LIGATION (LAL)}

Hypoplastic left heart syndrome (HLHS), is a rare but serious congenital heart defect, marked by an underdeveloped and nonfunctioning left ventricle and hypoplastic ascending and transverse aorta in association with stenosis or atresia of the mitral and/or aortic valves, and intra-uterine compensatory enlargement of right sided cardiac structures (Friedman et al., 1951; Noonan and Nadas, 1958). Left atrial ligation (LAL) in the chick embryo remains the only long term prenatal animal model of HLHS (Rychter, 1962). The presumptive left atrium is tied off, disrupting inflow to the left side of the embryonic ventricle (Figure 5). Immediately following LAL, intracardiac flow patterns shift ventrally (Kowalski et al., 2014). Downstream cardiac pressures are unchanged, but cardiac output is transiently reduced, returning to normal levels by $32 \mathrm{~h}$ post-LAL (Lucitti et al., 2005). Abnormal remodeling of the ventricular myocardium is observed after 2 days, including decreased myocardial volume, accelerated trabecular compaction, and delayed changes in transmural myofiber angle (Sedmera et al., 1999; Tobita et al., 2005). Circumferential and longitudinal strain increases in both ventricles after LAL, while the onset of preferential circumferential strain patterns in the right ventricle are accelerated and the preferential longitudinal strain patterns in the left ventricle are abolished (Tobita and Keller, 2000). At the cellular level, LAL results in reduced proliferation in the left ventricular 

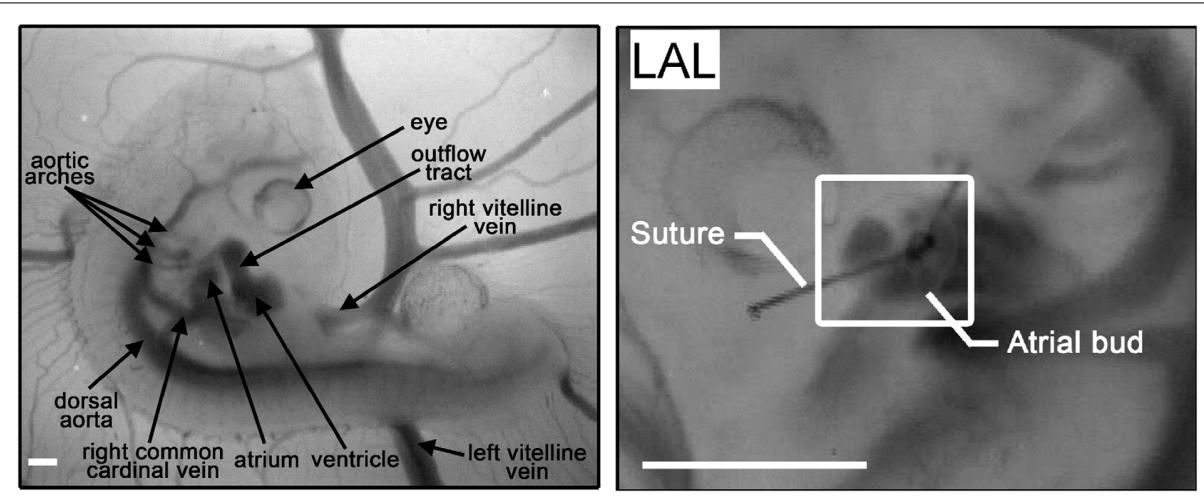

FIGURE 5 | HH21 chick embryo model. Right panel: a normal embryo viewed from the right lateral with major vascular structures labeled. Left panel: a repositioned left side up embryo after $L A L$ viewed from the left lateral to illustrate the ligated left atrium. Scale bars $=500 \mu m$.

compact layer and trabeculae, decreased FGF-2 and PDGF-B expression throughout the heart, a greater number of apoptotic cells in the right AV cushions, and increased microtubule density in the left ventricular compact layer (Schroder et al., 2002; Sedmera et al., 2002). Downstream vessels are also affected in LAL; flow distribution within the aortic arches is disrupted, and defects including aortic arch hypoplasia and interrupted aortic arch are observed as early as $32 \mathrm{~h}$ after ligation (Hu et al., 2009).

\section{OTHER HEMODYNAMIC INTERVENTIONS}

Altering heart rate is a simple method for disrupting CV function and examines how cycle length affects cardiac performance. In one study, heart rate altered by applying a heated or cooled metal probe to the sinus venosus of HH21 chick embryos, with simultaneous pressure-volume loop analysis (Casillas et al., 1994). End diastolic volume and stroke volume varied linearly with cycle length whereas end systolic pressure varied inversely. Interestingly, end diastolic pressure was not dependent on cycle length, and the heart was able to acutely increase stroke volume without an increase in developed ventricular pressure. As no functioning autonomic nervous system exists at $\mathrm{HH} 21$, the vascular response may be induced by flow, stretch, or endocrine mechanisms.

Vitelline artery ligation (VAL) is a method for increasing peripheral vascular resistance in chick embryos. VAL performed at $\mathrm{HH} 21$ resulted in reduced stroke volume and cardiac output, increased total vascular resistance, larger first harmonic and characteristic impedances, decreased arterial compliance, and transient changes in pulse pressure, hydraulic power, and oscillatory power, which all normalized by $\mathrm{HH} 27$ (Lucitti et al., 2005). Structural effects of VAL were investigated through pressure-inflation tests of excised dorsal aortae, which revealed an increased stiffness in VAL embryos (Lucitti et al., 2006). Smooth muscle $\alpha$-actin and collagen-III were present in greater amounts in the dorsal aortae of VAL embryos, demonstrating a remodeling response to the altered load (Lucitti et al., 2006).

Blood flow can be entirely eliminated in chick embryos by removing the heart at HH12. These embryos showed underdeveloped cranial and cervical regions and mesenchymal edema at $\mathrm{HH} 17$ as well as abnormal yolk sac vasculature (Manner et al.,
1995). Incubation in hyperoxic conditions achieved normal cervical growth and mesenchyme, but did not recover yolk sac remodeling, suggesting an early metabolic role for blood flow in cranial development whereas vascular remodeling depends primarily on the mechanical factors induced by blood flow (Manner et al., 1995). In a separate study, obliteration of blood flow in chick embryos was achieved by incubating with an open shell window, dehydrating the embryo, and resulted in arrested remodeling of the yolk sac vasculature with no arterial-venous differentiation (Le Noble et al., 2004). This study further demonstrated through a vitelline artery ligation model that arterial markers neuropilin 1 and ephrinB2 were downregulated on the ligated side while venous markers neuropilin 2 and Tie2 were upregulated (Le Noble et al., 2004). Upon removing the ligation, expression of neuropilin 1 returned. Thus, arterial-venous differentiation was not only influenced by flow conditions, but also adaptable to modified flow over a certain timeframe (ligations lasting more than $6 \mathrm{~h}$ did not return neuropilin 1 expression) (Jones et al., 2006). Flow occlusion in zebrafish embryos was achieved by inserting microbeads at the inflow or outflow regions, which resulted in abnormal cardiac chamber morphology and disrupted valve formation, demonstrating the importance of shear stress in the development of these structures (Hove et al., 2003).

Lowering blood viscosity by reducing hematocrit is an interesting approach to decrease WSS throughout the CV. In mouse embryos, primitive erythroblasts were sequestered in blood islands using polyacrylamide to reduce viscosity and therefore WSS (Lucitti et al., 2007). Under this decreased WSS, the yolk sac failed to remodel. Injecting viscous hetastarch was able to recover normal remodeling, however. These results suggest that WSS is the primary factor, rather than oxygen or nutrient delivery, for vascular remodeling in the embryo. In zebrafish embryos, blood viscosity was lowered by using morpholinos against gata1 (no blood cells) and gata2 (72\% less blood cells) (Vermot et al., 2009). This modified viscosity changed the reverse flow fraction at the AV canal from $35 \%$ normally to $45 \%$ in gatal morphants and $17 \%$ in gata 2 morphants. At later stages, most gata1 embryos had normal valves, while the majority of gata2 morphants developed valve defects, suggesting that reverse flows are critical for valve remodeling. Genetic zebrafish models such as silent heart (sih-/-), 
which lacks a heartbeat, and cardiofunk ( $c f k-/-)$, which exhibits cardiac dilation offer novel methods to investigate embryonic development under low- to no-flow conditions (Bartman et al., 2004).

Pharmacologic models have been used to generate transient alterations in embryonic hemodynamics by altering ventricular function and/or arterial afterload. Calcium channel blockade (verapamil) reduces ventricular contractility in the immature myocardium (Clark et al., 1991; Tenthorey et al., 1998), caffeine reduces ventricular function due to increased vascular impedance due to vasoconstriction (Bruyere et al., 1987, 1988; Momoi et al., 2008) and chronic hypoxia alters ventricular function due to mixed effects (reduced contractility and increased vascular resistance).

Computational modeling approaches discussed in Section Computational modeling approaches have been applied to investigate effects of the surgical interventions described above. Mechanical stress and strain was modeled in ventricle geometries obtained from normal, OTB, and verapamil suffused (pressureunderloaded) HH29 chick embryos (Buffinton et al., 2013). Flow in normal and in silico generated LAL HH21 heart geometries was modeled using CFD to examine flow patterns and WSS, though the static model was not sufficient to recapitulate experimental results (Kowalski et al., 2014).

\section{SUMMARY AND OUTLOOK}

Hemodynamic forces such as WSS and pressure provide biomechanical cues that stimulate growth and remodeling of the $\mathrm{CV}$ system. Experimental techniques to quantify this environment include velocimetry, pressure measurement, and dynamic in vivo imaging. These methods have identified several trends in hemodynamic parameters over development. Computational models complement these experiments and provide further insights into the biomechanical regulation of CV morphogenesis. Interventions to test the $\mathrm{CV}$ response to perturbed flow on a healthy/normal functioning genetic pathway demonstrate the role of hemodynamics and uncover important aspects of how blood flow influences CV growth. As these techniques and models advance, so will the understanding of CV development.

There is still a need for greater quantification of CV morphology in both normal and under experimentally perturbed conditions. Live imaging techniques that allow time-lapse, longterm studies are a promising prospect to quantify growth on a local and temporal scale. Real-time growth data can, in turn, be used to train predictive computational models. The inclusion of cellular and molecular methods to study the biologic mechanisms of biomechanical regulation is also greatly needed. Studies performed under in vivo conditions, rather than isolated in vitro tests, will be important to determine how hemodynamic force is converted into tissue remodeling. Additionally, a greater investigation of the mechanical properties of $\mathrm{CV}$ tissues is required to fully understand the effects of structural remodeling. Developing these areas is vital to ensure future discovery.

Investigating the critical biomechanical loading thresholds that regulate local vascular morphogenesis and remodeling is another rapidly expanding landscape. We anticipate that the cardiac chambers and vascular regions have unique vulnerabilities to altered biomechanical stresses, directly contributing to the range of abnormal morphologies found in children with CHD. While we cannot predict, a priori, the amplitude or duration required to trigger these critical events, it is likely that the mechanical and temporal thresholds will correspond to the thresholds required to transduce changes in biomechanical loading in to altered cellular fates (proliferation, maturation, death).

Defining the role of biomechanics in CV development creates opportunities for new treatment strategies for CHD. The current understanding of flow and growth relationships has been translated as a rationale for cardiac intervention in the mid-gestation human fetus and intervention in humans has shown that restoration toward normal biomechanical loading partially restores the growth and remodeling of left heart structures (mitral valve, aortic valve, aorta), though recovery of fetal myocardial growth after fetal intervention remains suboptimal (Pekkan et al., 2008a,b; McElhinney et al., 2010). The application of science and engineering approaches to study embryonic biomechanics will further our understanding of these relationships, potentially improving the outcomes for fetal intervention of CHD.

\section{ACKNOWLEDGMENTS}

The authors want to recognize the pioneering work of Dr. Edward B. Clark and Norman $\mathrm{Hu}$ who developed the experimental paradigm and methods to quantify cardiac structural and functional maturation during chick embryo cardiac morphogenesis and who have launched a generation of investigators in this field. This work was supported by NSF CAREER Award 0954465 (Kerem Pekkan) and the Kosair Charities Pediatric Heart Research Endowment (Bradley B. Keller).

\section{REFERENCES}

Al Naieb, S., Happel, C. M., and Yelbuz, T. M. (2012). A detailed atlas of chick heart development in vivo. Ann. Anat. 195, 185-193. doi: 10.1016/j.aanat.2012.10.011

Al-Roubaie, S., Jahnsen, E. D., Mohammed, M., Henderson-Toth, C., and Jones, E. A. (2011). Rheology of embryonic avian blood. Am. J. Physiol. Heart Circ. Physiol. 301, H2473-H2481. doi: 10.1152/ajpheart.00475.2011

Auerbach, R., Kubai, L., Knighton, D., and Folkman, J. (1974). A simple procedure for the long-term cultivation of chicken embryos. Dev. Biol. 41, 391-394.

Bahtiyar, M. O., and Copel, J. A. (2008). Cardiac changes in the intrauterine growth-restricted fetus. Semin. Perinatol. 32, 190-193. doi: 10.1053/j.semperi.2008.02.010

Bain, M. M., Fagan, A. J., Mullin, J. M., McNaught, I., McLean, J., and Condon, B. (2007). Noninvasive monitoring of chick development in ovo using a 7T MRI system from day 12 of incubation through to hatching. J. Magn. Reson. Imaging 26, 198-201. doi: 10.1002/jmri.20963

Baker, K., Holtzman, N. G., and Burdine, R. D. (2008). Direct and indirect roles for Nodal signaling in two axis conversions during asymmetric morphogenesis of the zebrafish heart. Proc. Natl. Acad. Sci. U.S.A. 105, 13924-13929. doi: 10.1073/pnas.0802159105

Bartman, T., Walsh, E. C., Wen, K. K., McKane, M., Ren, J., Alexander, J., et al. (2004). Early myocardial function affects endocardial cushion development in zebrafish. PLoS Biol. 2:E129. doi: 10.1371/journal.pbio.0020129

Bayer, I. M., Adamson, S. L., and Langille, B. L. (1999). Atrophic remodeling of the artery-cuffed artery. Arterioscler. Thromb. Vasc. Biol. 19, 1499-1505.

Bharadwaj, K. N., Spitz, C., Shekhar, A., Yalcin, H. C., and Butcher, J. T. (2012). Computational fluid dynamics of developing avian outflow tract heart valves. Ann. Biomed. Eng. 40, 2212-2227. doi: 10.1007/s10439-012-0574-8

Bhatt, S., Alison, B. J., Wallace, E. M., Crossley, K. J., Gill, A. W., Kluckow, M., et al. (2013). Delaying cord clamping until ventilation onset improves cardiovascular function at birth in preterm lambs. J. Physiol. 591, 2113-2126. doi: 10.1113/jphysiol.2012.250084 
Bremer, J. L. (1932). The presence and influence of two spiral streams in the heart of the chick embryo. Am. J. Anat. 49, 409-440. doi: 10.1002/aja.10004 90305

Broekhuizen, M. L., Hogers, B., Deruiter, M. C., Poelmann, R. E., Gittenberger-De Groot, A. C., and Wladimiroff, J. W. (1999). Altered hemodynamics in chick embryos after extraembryonic venous obstruction. Ultrasound Obstet. Gynecol. 13, 437-445. doi: 10.1046/j.1469-0705.1999.13060437.x

Broekhuizen, M. L., Mast, F., Struijk, P. C., Van Der Bie, W., Mulder, P. G., Gittenberger-De Groot, A. C., et al. (1993). Hemodynamic parameters of stage 20 to stage 35 chick embryo. Pediatr. Res. 34, 44-46.

Bruneau, B. G. (2008). The developmental genetics of congenital heart disease. Nature 451, 943-948. doi: 10.1038/nature06801

Bruyere, H. J. Jr., Michaud, B. J., Gilbert, E. F., and Folts, J. D. (1987). The effects of cardioteratogenic doses of caffeine on cardiac function in the 3-day chick embryo. J. Appl. Toxicol. 7, 197-203.

Bruyere, H. J. Jr., Noonan, J. J., Dong, S., Oberley, T. D., Schmidt, M. J., Gilbert, E. F, et al. (1988). The effects of caffeine on the ultrastructure and mitochondrial function of the embryonic chick heart. J. Appl. Toxicol. 8, 9-13.

Buffinton, C. M., Faas, D., and Sedmera, D. (2013). Stress and strain adaptation in load-dependent remodeling of the embryonic left ventricle. Biomech. Model. Mechanobiol. 12, 1037-1051. doi: 10.1007/s10237-012-0461-0

Burggren, W. (2013). Cardiovascular development and angiogenesis in the early vertebrate embryo. Cardiovasc. Eng. Technol. 4, 234-245. doi: 10.1007/s13239013-0118-x

Burggren, W. W., and Keller, B. B. (1998). Development of Cardiovascular Systems: Molecules to Organisms. New York, NY: Cambridge University Press.

Buskohl, P. R., Jenkins, J. T., and Butcher, J. T. (2012). Computational simulation of hemodynamic-driven growth and remodeling of embryonic atrioventricular valves. Biomech. Model. Mechanobiol. 11, 1205-1217. doi: 10.1007/s10237-0120424-5

Butcher, J. T., McQuinn, T. C., Sedmera, D., Turner, D., and Markwald, R. R. (2007a). Transitions in early embryonic atrioventricular valvular function correspond with changes in cushion biomechanics that are predictable by tissue composition. Circ. Res. 100, 1503-1511. doi: 10.1161/CIRCRESAHA.107. 148684

Butcher, J. T., Sedmera, D., Guldberg, R. E., and Markwald, R. R. (2007b). Quantitative volumetric analysis of cardiac morphogenesis assessed through micro-computed tomography. Dev. Dyn. 236, 802-809. doi: 10.1002/dvdy.20962

Casillas, C. B., Tinney, J. P., and Keller, B. B. (1994). Influence of acute alterations in cycle length on ventricular function in chick embryos. Am. J. Physiol. 267, H905-H911.

Chen, C.-Y., Menon, P. G., Kowalski, W., and Pekkan, K. (2012). Time-resolved OCT- $\mu$ PIV: a new microscopic PIV technique for noninvasive depth-resolved pulsatile flow profile acquisition. Exp. Fluids 54, 1-9. doi: 10.1007/s00348-0121426-X

Chen, C. Y., Patrick, M. J., Corti, P., Kowalski, W., Roman, B. L., and Pekkan, K. (2011). Analysis of early embryonic great-vessel microcirculation in zebrafish using high-speed confocal $\mu$ PIV. Biorheology 48, 305-321. doi: 10.3233/BIR2012-0600

Chen, J., Han, M., Manisastry, S. M., Trotta, P., Serrano, M. C., Huhta, J. C., et al. (2008). Molecular effects of lithium exposure during mouse and chick gastrulation and subsequent valve dysmorphogenesis. Birth Defects Res. A. Clin. Mol. Teratol. 82, 508-518. doi: 10.1002/bdra. 20448

Cheng, J. K., and Wagenseil, J. E. (2012). Extracellular matrix and the mechanics of large artery development. Biomech. Model. Mechanobiol. 11, 1169-1186. doi: 10.1007/s10237-012-0405-8

Chien, S. (2007). Mechanotransduction and endothelial cell homeostasis: the wisdom of the cell. Am. J. Physiol. Heart Circ. Physiol. 292, H1209-H1224. doi: 10.1152/ajpheart.01047.2006

Clark, E. B., and Hu, N. (1982). Developmental hemodynamic changes in the chick embryo from stage 18 to 27. Circ. Res. 51, 810-815.

Clark, E. B., Hu, N., Dummett, J. L., Vandekieft, G. K., Olson, C., and Tomanek, R. (1986). Ventricular function and morphology in chick embryo from stages 18 to 29. Am. J. Physiol. 250, H407-H413.

Clark, E. B., Hu, N., Frommelt, P., Vandekieft, G. K., Dummett, J. L., and Tomanek, R. J. (1989). Effect of increased pressure on ventricular growth in stage 21 chick embryos. Am. J. Physiol. 257, H55-H61.
Clark, E. B., Hu, N., Turner, D. R., Litter, J. E., and Hansen, J. (1991). Effect of chronic verapamil treatment on ventricular function and growth in chick embryos. Am. J. Physiol. 261, H166-H171.

Corti, P., Young, S., Chen, C. Y., Patrick, M. J., Rochon, E. R., Pekkan, K., et al. (2011). Interaction between alk1 and blood flow in the development of arteriovenous malformations. Development 138, 1573-1582. doi: 10.1242/dev.060467

Davis, A., Izatt, J., and Rothenberg, F. (2009). Quantitative measurement of blood flow dynamics in embryonic vasculature using spectral Doppler velocimetry. Anat. Rec. (Hoboken). 292, 311-319. doi: 10.1002/ar.20808

Davis, A. M., Rothenberg, F. G., Shepherd, N., and Izatt, J. A. (2008). In vivo spectral domain optical coherence tomography volumetric imaging and spectral Doppler velocimetry of early stage embryonic chicken heart development. J. Opt. Soc. Am. A. Opt. Image Sci. Vis. 25, 3134-3143. doi: 10.1364/JOSAA. 25.003134

Deruiter, M. C., Poelmann, R. E., Mentink, M. M., Vaniperen, L., and GittenbergerDe Groot, A. C. (1993). Early formation of the vascular system in quail embryos. Anat. Rec. 235, 261-274. doi: 10.1002/ar.1092350210

Desforges, M., and Sibley, C. P. (2010). Placental nutrient supply and fetal growth. Int. J. Dev. Biol. 54, 377-390. doi: 10.1387/ijdb.082765md

Egorova, A. D., Van Der Heiden, K., Van De Pas, S., Vennemann, P., Poelma, C., Deruiter, M. C., et al. (2011). Tgfbeta/Alk5 signaling is required for shear stress induced klf2 expression in embryonic endothelial cells. Dev. Dyn. 240, 1670-1680. doi: 10.1002/dvdy.22660

El-Ghali, N., Rabadi, M., Ezin, A. M., and De Bellard, M. E. (2010). New methods for chicken embryo manipulations. Microsc. Res. Tech. 73, 58-66. doi: 10.1002/jemt.20753

Faber, J. J., Green, T. J., and Thornburg, K. L. (1974). Embryonic stroke volume and cardiac output in the chick. Dev. Biol. 41, 14-21. doi: 10.1016/0012-1606 (74) $90278-4$

Falchuk, K. H., and Berliner, R. W. (1971). Hydrostatic pressures in peritubular capillaries and tubules in the rat kidney. Am. J. Physiol. 220, 1422-1426.

Ferrazzi, E., Rigano, S., Bozzo, M., Bellotti, M., Giovannini, N., Galan, H., et al. (2000). Umbilical vein blood flow in growth-restricted fetuses. Ultrasound Obstet. Gynecol. 16, 432-438. doi: 10.1046/j.1469-0705.2000.00208.x

Forouhar, A. S., Liebling, M., Hickerson, A., Nasiraei-Moghaddam, A., Tsai, H. J., Hove, J. R., et al. (2006). The embryonic vertebrate heart tube is a dynamic suction pump. Science 312, 751-753. doi: 10.1126/science.1123775

Friedman, S., Murphy, L., and Ash, R. (1951). Aortic atresia with hypoplasia of the left heart and aortic arch. J. Pediatr. 38, 354-368.

Fung, Y. C. (1997). Biomechanics: Circulation. New York, NY: Springer.

Fung, Y. C., and Liu, S. Q. (1991). Changes of zero-stress state of rat pulmonary arteries in hypoxic hypertension. J. Appl. Physiol. 70, 2455-2470.

Furukawa, S., Tinney, J. P., Tobita, K., and Keller, B. B. (2007). Hemodynamic vulnerability to acute hypoxia in day 10.5-16.5 murine embryos. J. Obstet. Gynaecol. Res. 33, 114-127. doi: 10.1111/j.1447-0756.2007.00499.x

Gadelha Da Costa, A., Mauad Filho, F., Spara, P., Barreto Gadelha, E., and Vieira Santana Netto, P. (2005). Fetal hemodynamics evaluated by Doppler velocimetry in the second half of pregnancy. Ultrasound Med. Biol. 31, 1023-1030. doi: 10.1016/j.ultrasmedbio.2005.04.009

Gargesha, M., Jenkins, M. W., Wilson, D. L., and Rollins, A. M. (2009). High temporal resolution OCT using image-based retrospective gating. Opt. Express 17, 10786-10799. doi: 10.1364/OE.17.010786

Girerd, X., London, G., Boutouyrie, P., Mourad, J. J., Safar, M., and Laurent, S. (1996). Remodeling of the radial artery in response to a chronic increase in shear stress. Hypertension 27, 799-803.

Glickman, N. S., and Yelon, D. (2002). Cardiac development in zebrafish: coordination of form and function. Semin. Cell Dev. Biol. 13, 507-513. doi: 10.1016/S1084952102001040

Go, A. S., Mozaffarian, D., Roger, V. L., Benjamin, E. J., Berry, J. D., Borden, W. B., et al. (2013). Heart disease and stroke statistics-2013 update: a report from the American Heart Association. Circulation 127, e6-e245. doi: 10.1161/CIR.0b013e31828124ad

Gregg, C. L., and Butcher, J. T. (2012). Quantitative in vivo imaging of embryonic development: opportunities and challenges. Differentiation 84, 149-162. doi: 10.1016/j.diff.2012.05.003

Groenendijk, B. C., Hierck, B. P., Vrolijk, J., Baiker, M., Pourquie, M. J., Gittenberger-De Groot, A. C., et al. (2005). Changes in shear stress-related gene expression after experimentally altered venous return in the chicken embryo. Circ. Res. 96, 1291-1298. doi: 10.1161/01.RES.0000171901.40952.0d 
Gruionu, G., Hoying, J. B., Pries, A. R., and Secomb, T. W. (2005). Structural remodeling of mouse gracilis artery after chronic alteration in blood supply. Am. J. Physiol. Heart Circ. Physiol. 288, H2047-H2054. doi: 10.1152/ajpheart.00496.2004

Gui, Y. H., Linask, K. K., Khowsathit, P., and Huhta, J. C. (1996). Doppler echocardiography of normal and abnormal embryonic mouse heart. Pediatr. Res. 40, 633-642. doi: 10.1203/00006450-199610000-00020

Guyton, J. R., and Hartley, C. J. (1985). Flow restriction of one carotid artery in juvenile rats inhibits growth of arterial diameter. Am. J. Physiol. 248, H540-H546.

Hamburger, V., and Hamilton, H. L. (1951). A series of normal stages in the development of the chick embryo. J. Morphol. 88, 49-92.

Happel, C. M., Thrane, L., Thommes, J., Manner, J., and Yelbuz, T. M. (2011). Integration of an optical coherence tomography (OCT) system into an examination incubator to facilitate in vivo imaging of cardiovascular development in higher vertebrate embryos under stable physiological conditions. Ann. Anat. 193, 425-435. doi: 10.1016/j.aanat.2011.04.006

Heineman, F. W., and Grayson, J. (1985). Transmural distribution of intramyocardial pressure measured by micropipette technique. Am. J. Physiol. 249, H1216-H1223.

Hendrix, N., and Berghella, V. (2008). Non-placental causes of intrauterine growth restriction. Semin. Perinatol. 32, 161-165. doi: 10.1053/j.semperi.2008.02.004

Henning, A. L., Jiang, M. X., Yalcin, H. C., and Butcher, J. T. (2011). Quantitative three-dimensional imaging of live avian embryonic morphogenesis via microcomputed tomography. Dev. Dyn. 240, 1949-1957. doi: 10.1002/dvdy.22694

Hogers, B., Deruiter, M. C., Baasten, A. M., Gittenberger-De Groot, A. C., and Poelmann, R. E. (1995). Intracardiac blood flow patterns related to the yolk sac circulation of the chick embryo. Circ. Res. 76, 871-877.

Hogers, B., Deruiter, M. C., Gittenberger-De Groot, A. C., and Poelmann, R. E. (1999). Extraembryonic venous obstructions lead to cardiovascular malformations and can be embryo lethal. Cardiovasc. Res. 41, 87-99.

Holmes, W. M., McCabe, C., Mullin, J. M., Condon, B., and Bain, M. M. (2009). In ovo non-invasive quantification of the myocardial function and mass of chick embryos using magnetic resonance imaging. NMR Biomed. 22, 745-752. doi: $10.1002 / \mathrm{nbm} .1386$

Hove, J. R., Koster, R. W., Forouhar, A. S., Acevedo-Bolton, G., Fraser, S. E., and Gharib, M. (2003). Intracardiac fluid forces are an essential epigenetic factor for embryonic cardiogenesis. Nature 421, 172-177. doi: 10.1038/nature01282

Hu, N., Christensen, D. A., Agrawal, A. K., Beaumont, C., Clark, E. B., and Hawkins, J. A. (2009). Dependence of aortic arch morphogenesis on intracardiac blood flow in the left atrial ligated chick embryo. Anat. Rec. (Hoboken). 292, 652-660. doi: $10.1002 /$ ar.20885

Hu, N., and Clark, E. B. (1989). Hemodynamics of the stage 12 to stage 29 chick embryo. Circ. Res. 65, 1665-1670.

$\mathrm{Hu}, \mathrm{N}$., and Keller, B. B. (1995). Relationship of simultaneous atrial and ventricular pressures in stage 16-27 chick embryos. Am. J. Physiol. 269, H1359-H1362.

Huang, C., Sheikh, F., Hollander, M., Cai, C., Becker, D., Chu, P. H., et al. (2003). Embryonic atrial function is essential for mouse embryogenesis, cardiac morphogenesis and angiogenesis. Development 130, 6111-6119. doi: $10.1242 /$ dev.00831

Hughes, A. F. W. (1934). On the development of the blood vessels in the head of the chick. Philos. Trans. R. Soc. Lond. B, Biol. Sci. 224, U75-U42.

Hungerford, J. E., Owens, G. K., Argraves, W. S., and Little, C. D. (1996). Development of the aortic vessel wall as defined by vascular smooth muscle and extracellular matrix markers. Dev. Biol. 178, 375-392. doi: 10.1006/dbio.1996.0225

Hutchon, D. J. (2013). Early vs delayed cord clamping at birth; in sickness and in health. Fetal Matern. Med. Rev. 24, 185-193. doi: 10.1017/S0965539513000120

Intengan, H. D., Deng, L. Y., Li, J. S., and Schiffrin, E. L. (1999a). Mechanics and composition of human subcutaneous resistance arteries in essential hypertension. Hypertension 33, 569-574.

Intengan, H. D., Thibault, G., Li, J. S., and Schiffrin, E. L. (1999b). Resistance artery mechanics, structure, and extracellular components in spontaneously hypertensive rats: effects of angiotensin receptor antagonism and converting enzyme inhibition. Circulation 100, 2267-2275.

Ishiwata, T., Nakazawa, M., Pu, W. T., Tevosian, S. G., and Izumo, S. (2003). Developmental changes in ventricular diastolic function correlate with changes in ventricular myoarchitecture in normal mouse embryos. Circ. Res. 93, 857-865. doi: 10.1161/01.RES.0000100389.57520.1A
Isogai, S., Horiguchi, M., and Weinstein, B. M. (2001). The vascular anatomy of the developing zebrafish: an atlas of embryonic and early larval development. Dev. Biol. 230, 278-301. doi: 10.1006/dbio.2000.9995

Jaffee, O. C. (1965). Hemodynamic factors in the development of the chick embryo heart. Anat. Rec. 151, 69-75.

Jenkins, M. W., Peterson, L., Gu, S., Gargesha, M., Wilson, D. L., Watanabe, M., et al. (2010). Measuring hemodynamics in the developing heart tube with fourdimensional gated Doppler optical coherence tomography. J. Biomed. Opt. 15, 066022. doi: 10.1117/1.3509382

Jones, E. A., Le Noble, F., and Eichmann, A. (2006). What determines blood vessel structure? genetic prespecification vs. hemodynamics. Physiology (Bethesda) 21, 388-395. doi: 10.1152/physiol.00020.2006

Kamei, M., and Weinstein, B. M. (2005). Long-term time-lapse fluorescence imaging of developing zebrafish. Zebrafish 2, 113-123. doi: 10.1089/zeb.2005.2.113

Kamiya, A., and Togawa, T. (1980). Adaptive regulation of wall shear stress to flow change in the canine carotid artery. Am. J. Physiol. 239, H14-H21.

Karunamuni, G., Gu, S., Doughman, Y. Q., Peterson, L. M., Mai, K., McHale, Q., et al. (2014). Ethanol exposure alters early cardiac function in the looping heart: a mechanism for congenital heart defects? Am. J. Physiol. Heart Circ. Physiol. 306, H414-H421. doi: 10.1152/ajpheart.00600.2013

Keller, B. B., Hu, N., and Clark, E. B. (1990). Correlation of ventricular area, perimeter, and conotruncal diameter with ventricular mass and function in the chick embryo from stages 12 to 24. Circ. Res. 66, 109-114.

Keller, B. B., Hu, N., Serrino, P. J., and Clark, E. B. (1991). Ventricular pressure-area loop characteristics in the stage 16 to 24 chick embryo. Circ. Res. 68, 226-231.

Keller, B. B., Maclennan, M. J., Tinney, J. P., and Yoshigi, M. (1996). In vivo assessment of embryonic cardiovascular dimensions and function in day- 10.5 to -14.5 mouse embryos. Circ. Res. 79, 247-255.

Kim, J. S., Min, J., Recknagel, A. K., Riccio, M., and Butcher, J. T. (2011). Quantitative three-dimensional analysis of embryonic chick morphogenesis via microcomputed tomography. Anat. Rec. (Hoboken). 294, 1-10. doi: 10.1002/ar.21336

Kowalski, W. J., Dur, O., Wang, Y., Patrick, M. J., Tinney, J. P., Keller, B. B., et al. (2013). Critical transitions in early embryonic aortic arch patterning and hemodynamics. PLoS ONE 8:e60271. doi: 10.1371/journal.pone.00 60271

Kowalski, W. J., Teslovich, N. C., Dur, O., Keller, B. B., and Pekkan, K. (2012). Computational hemodynamic optimization predicts dominant aortic arch selection is driven by embryonic outflow tract orientation in the chick embryo. Biomech. Model. Mechanobiol. 11, 1057-1073. doi: 10.1007/s10237-012-0373-z

Kowalski, W. J., Teslovich, N. C., Menon, P. G., Tinney, J. P., Keller, B. B., and Pekkan, K. (2014). Left atrial ligation alters intracardiac flow patterns and the biomechanical landscape in the chick embryo. Dev. Dyn. 243, 652-662. doi: 10.1002/dvdy. 24107

Krebs, C., Longo, L. D., and Leiser, R. (1997). Term ovine placental vasculature: comparison of sea level and high altitude conditions by corrosion cast and histomorphometry. Placenta 18, 43-51.

Kulesa, P. M., Bailey, C. M., Cooper, C., and Fraser, S. E. (2010). In ovo live imaging of avian embryos. Cold Spring Harb Protoc. 2010. doi: 10.1101/pdb.prot5446

Langille, B. L., and O'donnell, F. (1986). Reductions in arterial diameter produced by chronic decreases in blood flow are endothelium-dependent. Science 231, 405-407.

Larina, I. V., Sudheendran, N., Ghosn, M., Jiang, J., Cable, A., Larin, K. V., et al. (2008). Live imaging of blood flow in mammalian embryos using Doppler swept-source optical coherence tomography. J. Biomed. Opt. 13, 060506. doi: 10.1117/1.3046716

Le Noble, F., Moyon, D., Pardanaud, L., Yuan, L., Djonov, V., Matthijsen, R., et al. (2004). Flow regulates arterial-venous differentiation in the chick embryo yolk sac. Development 131, 361-375. doi: 10.1242/dev.00929

Levine, A. J., Munoz-Sanjuan, I., Bell, E., North, A. J., and Brivanlou, A. H. (2003). Fluorescent labeling of endothelial cells allows in vivo, continuous characterization of the vascular development of Xenopus laevis. Dev. Biol. 254, 50-67. doi: $10.1016 /$ S0012-1606(02)00029-5

Liu, A., Nickerson, A., Troyer, A., Yin, X., Cary, R., Thornburg, K., et al. (2011). Quantifying blood flow and wall shear stresses in the outflow tract of chick embryonic hearts. Comput. Struct. 89, 855-867. doi: 10.1016/j.compstruc.2011.03.003

Liu, A., Yin, X., Shi, L., Li, P., Thornburg, K. L., Wang, R., et al. (2012). Biomechanics of the chick embryonic heart outflow tract at HH18 using 4D 
optical coherence tomography imaging and computational modeling. PLoS ONE 7:e40869. doi: 10.1371/journal.pone.0040869

Lohr, J. L., and Yost, H. J. (2000). Vertebrate model systems in the study of early heart development: Xenopus and zebrafish. Am. J. Med. Genet. 97, 248-257. doi: 10.1002/1096-8628(200024)97:4<248::AID-AJMG1275>3.0.CO;2-C

Lucitti, J. L., Jones, E. A., Huang, C., Chen, J., Fraser, S. E., and Dickinson, M. E. (2007). Vascular remodeling of the mouse yolk sac requires hemodynamic force. Development 134, 3317-3326. doi: 10.1242/dev.02883

Lucitti, J. L., Tobita, K., and Keller, B. B. (2005). Arterial hemodynamics and mechanical properties after circulatory intervention in the chick embryo. J. Exp. Biol.208, 1877-1885. doi: 10.1242/jeb.01574

Lucitti, J. L., Visconti, R., Novak, J., and Keller, B. B. (2006). Increased arterial load alters aortic structural and functional properties during embryogenesis. Am. J. Physiol. Heart Circ. Physiol. 291, H1919-H1926. doi: 10.1152/ajpheart.01061.2005

Ma, Z., Liu, A., Yin, X., Troyer, A., Thornburg, K., Wang, R. K., et al. (2010). Measurement of absolute blood flow velocity in outflow tract of $\mathrm{HH} 18$ chicken embryo based on 4D reconstruction using spectral domain optical coherence tomography. Biomed. Opt. Express 1, 798-811. doi: 10.1364/BOE.1.000798

Majesky, M. W., Dong, X. R., Regan, J. N., and Hoglund, V. J. (2011). Vascular smooth muscle progenitor cells: building and repairing blood vessels. Circ. Res. 108, 365-377. doi: 10.1161/CIRCRESAHA.110.223800

Manner, J. (2009). The anatomy of cardiac looping: a step towards the understanding of the morphogenesis of several forms of congenital cardiac malformations. Clin. Anat. 22, 21-35. doi: 10.1002/ca.20652

Manner, J., Seidl, W., and Steding, G. (1995). Formation of the cervical flexure: an experimental study on chick embryos. Acta Anat. (Basel). 152, 1-10.

Manner, J., Thrane, L., Norozi, K., and Yelbuz, T. M. (2008). High-resolution in vivo imaging of the cross-sectional deformations of contracting embryonic heart loops using optical coherence tomography. Dev. Dyn. 237, 953-961. doi: 10.1002/dvdy.21483

Martinsen, B. J. (2005). Reference guide to the stages of chick heart embryology. Dev. Dyn. 233, 1217-1237. doi: 10.1002/dvdy.20468

May, S. R., Stewart, N. J., Chang, W., and Peterson, A. S. (2004). A Titin mutation defines roles for circulation in endothelial morphogenesis. Dev. Biol. 270, 31-46. doi: 10.1016/j.ydbio.2004.02.006

McElhinney, D. B., Tworetzky, W., and Lock, J. E. (2010). Current status of fetal cardiac intervention. Circulation 121, 1256-1263. doi: 10.1161/CIRCULATIONAHA.109.870246

Miller, C. E., Wong, C. L., and Sedmera, D. (2003). Pressure overload alters stressstrain properties of the developing chick heart. Am. J. Physiol. Heart Circ. Physiol. 285, H1849-H1856. doi: 10.1152/ajpheart.00384.2002

Momoi, N., Tinney, J. P., Liu, L. J., Elshershari, H., Hoffmann, P. J., Ralphe, J. C., et al. (2008). Modest maternal caffeine exposure affects developing embryonic cardiovascular function and growth. Am. J. Physiol. Heart Circ. Physiol. 294, H2248-H2256. doi: 10.1152/ajpheart.91469.2007

Nieuwkoop, P. D., and Faber, J. (1994). Normal Table of Xenopus Laevis (Daudin): A Systematical and Chronological Survey of the Development from the Fertilized Egg Till the End of Metamorphosis. New York, NY: Garland Pub.

Nissen, R., Cardinale, G. J., and Udenfriend, S. (1978). Increased turnover of arterial collagen in hypertensive rats. Proc. Natl. Acad. Sci. U.S.A. 75, 451-453.

Noonan, J. A., and Nadas, A. S. (1958). The hypoplastic left heart syndrome; an analysis of 101 cases. Pediatr. Clin. North Am. 5, 1029-1056.

Olivetti, G., Anversa, P., Melissari, M., and Loud, A. V. (1980). Morphometry of medial hypertrophy in the rat thoracic aorta. Lab. Invest. 42, 559-565.

Oosterbaan, A. M., Ursem, N. T., Struijk, P. C., Bosch, J. G., Van Der Steen, A. F., and Steegers, E. A. (2009). Doppler flow velocity waveforms in the embryonic chicken heart at developmental stages corresponding to 5-8 weeks of human gestation. Ultrasound Obstet. Gynecol. 33, 638-644. doi: 10.1002/uog.6362

O'rahilly, R. (1971). The timing and sequence of events in human cardiogenesis. Acta Anat. (Basel). 79, 70-75.

O'rahilly, R., and Muller, F. (2010). Developmental stages in human embryos: revised and new measurements. Cells Tissues Organs 192, 73-84. doi: 10.1159/000289817

O'rahilly, R., MuĺLler, F., and Streeter, G. L. (1987). Developmental Stages in Human Embryos: Including a Revision of Streeter's "Horizons" and a Survey of the Carnegie Collection. Washington, DC: Carnegie Institution of Washington.

Orhan, G., Baron, S., Norozi, K., Manner, J., Hornung, O., Blume, H., et al. (2007). Construction and establishment of a new environmental chamber to study real-time cardiac development. Microsc. Microanal. 13, 204-210. doi: $10.1017 /$ S1431927607070390

Pardi, G., Cetin, I., Marconi, A. M., Lanfranchi, A., Bozzetti, P., Ferrazzi, E., et al. (1993). Diagnostic value of blood sampling in fetuses with growth retardation. N. Engl. J. Med. 328, 692-696. doi: 10.1056/NEJM199303113281004

Patten, B. M. (1920). The Early Embryology of the Chick. Philadelphia, PA: P. Blakiston's Son \& Co.

Pekkan, K., Dur, O., Sundareswaran, K., Kanter, K., Fogel, M., Yoganathan, A., et al. (2008a). Neonatal aortic arch hemodynamics and perfusion during cardiopulmonary bypass. J. Biomech. Eng. 130, 061012. doi: 10.1115/1.2978988

Pekkan, K., and Keller, B. (2013). Fetal and embryonic hemodynamics: developmental fetal cardiovascular biomechanics in the 21st century: another tipping point. Cardiovasc. Eng. Technol. 4, 231-233. doi: 10.1007/s13239-013-0152-8

Pekkan, K., Whited, B., Kanter, K., Sharma, S., De Zelicourt, D., Sundareswaran, K., et al. (2008b). Patient-specific surgical planning and hemodynamic computational fluid dynamics optimization through free-form haptic anatomy editing tool (SURGEM). Med. Biol. Eng. Comput. 46, 1139-1152. doi: 10.1007/s11517008-0377-0

Peterson, L. M., Jenkins, M. W., Gu, S., Barwick, L., Watanabe, M., and Rollins, A. M. (2012). 4D shear stress maps of the developing heart using Doppler optical coherence tomography. Biomed. Opt. Express 3, 3022-3032. doi: 10.1364/BOE.3.003022

Phoon, C. K., Aristizabal, O., and Turnbull, D. H. (2000). 40 MHz Doppler characterization of umbilical and dorsal aortic blood flow in the early mouse embryo. Ultrasound Med. Biol. 26, 1275-1283. doi: 10.1016/S0301-5629(00)00278-7

Poelma, C., Kloosterman, A., Hierck, B. P., and Westerweel, J. (2012). Accurate blood flow measurements: are artificial tracers necessary? PLoS ONE 7:e45247. doi: 10.1371/journal.pone.0045247

Poelma, C., Van Der Heiden, K., Hierck, B. P., Poelmann, R. E., and Westerweel, J. (2010). Measurements of the wall shear stress distribution in the outflow tract of an embryonic chicken heart. J. R. Soc. Interface 7, 91-103. doi: 10.1098/rsif.2009.0063

Poelma, C., Vennemann, P., Lindken, R., and Westerweel, J. (2008). In vivo blood flow and wall shear stress measurements in the vitelline network. Exp. Fluids 45, 703-713. doi: 10.1007/s00348-008-0476-6

Raju, T. N. (2013). Timing of umbilical cord clamping after birth for optimizing placental transfusion. Curr. Opin. Pediatr. 25, 180-187. doi: 10.1097/MOP.0b013e32835d2a9e

Regnault, T. R., De Vrijer, B., Galan, H. L., Davidsen, M. L., Trembler, K. A., Battaglia, F. C., et al. (2003). The relationship between transplacental O2 diffusion and placental expression of PlGF, VEGF and their receptors in a placental insufficiency model of fetal growth restriction. J. Physiol. 550, 641-656. doi: 10.1113/jphysiol.2003.039511

Reynolds, L. P., Borowicz, P. P., Caton, J. S., Vonnahme, K. A., Luther, J. S., Buchanan, D. S., et al. (2010). Uteroplacental vascular development and placental function: an update. Int. J. Dev. Biol. 54, 355-366. doi: 10.1387/ijdb.082799lr

Reynolds, L. P., Borowicz, P. P., Vonnahme, K. A., Johnson, M. L., Grazul-Bilska, A. T., Redmer, D. A., et al. (2005). Placental angiogenesis in sheep models of compromised pregnancy. J. Physiol. 565, 43-58. doi: 10.1113/jphysiol.2004.081745

Reynolds, L. P., Ferrell, C. L., Robertson, D. A., and Ford, S. P. (1986). Metabolism of the gravid uterus, fetus and utero-placenta at several stages of gestation in cows. J. Agric. Sci. 106, 437-444.

Reynolds, L. P., and Redmer, D. A. (1995). Utero-placental vascular development and placental function. J. Anim. Sci. 73, 1839-1851.

Ribatti, D. (2006). Genetic and epigenetic mechanisms in the early development of the vascular system. J. Anat. 208, 139-152. doi: 10.1111/j.14697580.2006.00522.x

Robertson, A., Hill, M., and Li, D. (2012). "Structurally motivated damage models for arterial walls. Theory and application," in Modeling of Physiological Flows, eds. D. Ambrosi, A. Quarteroni and G. Rozza (Milan: Springer), 143-185.

Romanoff, A. L. (1960). The Avian Embryo; Structural and Functional Development. New York, NY: Macmillan.

Rudolph, A. M., and Heymann, M. A. (1970). Circulatory changes during growth in the fetal lamb. Circ. Res. 26, 289-299.

Rugonyi, S., Shaut, C., Liu, A., Thornburg, K., and Wang, R. K. (2008). Changes in wall motion and blood flow in the outflow tract of chick embryonic hearts observed with optical coherence tomography after outflow tract banding and vitelline-vein ligation. Phys. Med. Biol. 53, 5077-5091. doi: 10.1088/00319155/53/18/015 
Rychter, Z. (1962). Experimental morphology of the aortic arches and the heart loop in chick embryos. Adv. Morphog. 2, 333-371.

Rychter, Z., Kopecky, M., and Lemez, L. (1955). A micromethod for determination of the circulating blood volume in chick embryos. Nature 175, 1126-1127.

Rychter, Z., and Lemez, L. (1965). Changes in localization in aortic arches of laminar blood streams of main venous trunks to heart after exclusion of vitelline vessels on second day of incubation. Fed. Proc. Transl. Suppl. 24, 815-820.

Savolainen, S. M., Foley, J. F., and Elmore, S. A. (2009). Histology atlas of the developing mouse heart with emphasis on E11.5 to E18.5. Toxicol. Pathol. 37, 395-414. doi: 10.1177/0192623309335060

Schroder, E. A., Tobita, K., Tinney, J. P., Foldes, J. K., and Keller, B. B. (2002). Microtubule involvement in the adaptation to altered mechanical load in developing chick myocardium. Circ. Res. 91, 353-359. doi: 10.1161/01.RES.0000030179.78135.FA

Sedmera, D., Hu, N., Weiss, K. M., Keller, B. B., Denslow, S., and Thompson, R. P. (2002). Cellular changes in experimental left heart hypoplasia. Anat. Rec. 267, 137-145. doi: 10.1002/ar.10098

Sedmera, D., Pexieder, T., Rychterova, V., Hu, N., and Clark, E. B. (1999). Remodeling of chick embryonic ventricular myoarchitecture under experimentally changed loading conditions. Anat. Rec. 254, 238-252. doi: 10.1002/(SICI) 1097-0185(19990201)254:2<238::AID-AR10>3.0.CO;2-V

Sedmera, D., Pexieder, T., Vuillemin, M., Thompson, R. P., and Anderson, R. H. (2000). Developmental patterning of the myocardium. Anat. Rec. 258, 319-337. doi: 10.1002/(SICI) 1097-0185(20000401)258:4<319::AID-AR1 > 3.0.CO;2-O

Seidelmann, S. B., Lighthouse, J. K., and Greif, D. M. (2014). Development and pathologies of the arterial wall. Cell. Mol. Life Sci. 71, 1977-1999. doi: 10.1007/s00018-013-1478-y

Sissman, N. J. (1970). Developmental landmarks in cardiac morphogenesis: comparative chronology. Am. J. Cardiol. 25, 141-148.

Sommers, R., Stonestreet, B. S., Oh, W., Laptook, A., Yanowitz, T. D., Raker, C., et al. (2012). Hemodynamic effects of delayed cord clamping in premature infants. Pediatrics 129, e667-e672. doi: 10.1542/peds.2011-2550

Stekelenburg-De Vos, S., Steendijk, P., Ursem, N. T., Wladimiroff, J. W., Delfos, R., and Poelmann, R. E. (2005). Systolic and diastolic ventricular function assessed by pressure-volume loops in the stage 21 venous clipped chick embryo. Pediatr. Res. 57, 16-21. doi: 10.1203/01.PDR.0000147734.53277.75

Stekelenburg-De Vos, S., Ursem, N. T., Hop, W. C., Wladimiroff, J. W., Gittenberger-De Groot, A. C., and Poelmann, R. E. (2003). Acutely altered hemodynamics following venous obstruction in the early chick embryo. J. Exp. Biol. 206, 1051-1057. doi: 10.1242/jeb.00216

Taber, L. A., and Chabert, S. (2002). Theoretical and experimental study of growth and remodeling in the developing heart. Biomech. Model. Mechanobiol. 1, 29-43. doi: 10.1007/s10237-002-0002-3

Teddy, J. M., Lansford, R., and Kulesa, P. M. (2005). Four-color, 4-D timelapse confocal imaging of chick embryos. Biotechniques 39, 703-710. doi: $10.2144 / 00011201$

Tedgui, A., Merval, R., and Esposito, B. (1992). Albumin transport characteristics of rat aorta in early phase of hypertension. Circ. Res. 71, 932-942.

Tenthorey, D., De Ribaupierre, Y., Kucera, P., and Raddatz, E. (1998). Effects of verapamil and ryanodine on activity of the embryonic chick heart during anoxia and reoxygenation. J. Cardiovasc. Pharmacol. 31, 195-202.

Theiler, K. (1972). The House Mouse; Development and Normal Stages from Fertilization to 4 Weeks of Age. New York, NY: Springer-Verlag.

Thoma, R. (1893). Untersuchungen über die Histogenese und Histomechanik des Gefässsystems. Stuttgart: Verlag von Ferdinand Enke.

Tobita, K., Garrison, J. B., Liu, L. J., Tinney, J. P., and Keller, B. B. (2005). Three-dimensional myofiber architecture of the embryonic left ventricle during normal development and altered mechanical loads. Anat. Rec. A. Discov. Mol. Cell. Evol. Biol. 283, 193-201. doi: 10.1002/ar.a.20133

Tobita, K., and Keller, B. B. (2000). Right and left ventricular wall deformation patterns in normal and left heart hypoplasia chick embryos. Am. J. Physiol. Heart Circ. Physiol. 279, H959-H969.

Tobita, K., Schroder, E. A., Tinney, J. P., Garrison, J. B., and Keller, B. B. (2002). Regional passive ventricular stress-strain relations during development of altered loads in chick embryo. Am. J. Physiol. Heart Circ. Physiol. 282, H2386-H2396. doi: 10.1152/ajpheart.00879.2001

Turnbull, D. H., Bloomfield, T. S., Baldwin, H. S., Foster, F. S., and Joyner, A. L. (1995). Ultrasound backscatter microscope analysis of early mouse embryonic brain development. Proc. Natl. Acad. Sci. U.S.A. 92, 2239-2243.
Ursem, N. T., Struijk, P. C., Poelmann, R. E., Gittenberger-De Groot, A. C., and Wladimiroff, J. W. (2001). Dorsal aortic flow velocity in chick embryos of stage 16 to 28. Ultrasound Med. Biol. 27, 919-924. doi: 10.1016/S03015629(01)00393-3

Van Den Berg, G., and Moorman, A. F. (2011). Development of the pulmonary vein and the systemic venous sinus: an interactive 3D overview. PLoS ONE 6:e22055. doi: 10.1371/journal.pone.0022055

Vennemann, P., Kiger, K. T., Lindken, R., Groenendijk, B. C., Stekelenburg-De Vos, S., Ten Hagen, T. L., et al. (2006). In vivo micro particle image velocimetry measurements of blood-plasma in the embryonic avian heart. J. Biomech. 39, 1191-1200. doi: 10.1016/j.jbiomech.2005.03.015

Vermot, J., Forouhar, A. S., Liebling, M., Wu, D., Plummer, D., Gharib, M., et al. (2009). Reversing blood flows act through klf2a to ensure normal valvulogenesis in the developing heart. PLoS Biol. 7:e1000246. doi: 10.1371/journal.pbio. 1000246

Wagenseil, J. E., Ciliberto, C. H., Knutsen, R. H., Levy, M. A., Kovacs, A., and Mecham, R. P. (2009). Reduced vessel elasticity alters cardiovascular structure and function in newborn mice. Circ. Res. 104, 1217-1224. doi: 10.1161/CIRCRESAHA.108.192054

Wagenseil, J. E., and Mecham, R. P. (2009). Vascular extracellular matrix and arterial mechanics. Physiol. Rev. 89, 957-989. doi: 10.1152/physrev.000 41.2008

Waldo, K. L., Kumiski, D., and Kirby, M. L. (1996). Cardiac neural crest is essential for the persistence rather than the formation of an arch artery. Dev Dyn. 205, 281-292. doi: 10.1002/(SICI) 1097-0177(199603)205:3<281::AIDAJA8 > 3.0.CO;2-E

Wallace, J. M., Regnault, T. R., Limesand, S. W., Hay, W. W. Jr., and Anthony, R. V. (2005). Investigating the causes of low birth weight in contrasting ovine paradigms. J. Physiol. 565, 19-26. doi: 10.1113/jphysiol.2004.082032

Wang, Y., Dur, O., Patrick, M. J., Tinney, J. P., Tobita, K., Keller, B. B., et al. (2009). Aortic arch morphogenesis and flow modeling in the chick embryo. Ann. Biomed. Eng. 37, 1069-1081. doi: 10.1007/s10439-009-9682-5

Wong, M. D., Dorr, A. E., Walls, J. R., Lerch, J. P., and Henkelman, R. M. (2012). A novel 3D mouse embryo atlas based on micro-CT. Development 139, 3248-3256. doi: 10.1242/dev.082016

Yalcin, H. C., Shekhar, A., McQuinn, T. C., and Butcher, J. T. (2011). Hemodynamic patterning of the avian atrioventricular valve. Dev. Dyn. 240, 23-35. doi: 10.1002/dvdy.22512

Yalcin, H. C., Shekhar, A., Rane, A. A., and Butcher, J. T. (2010). An ex-ovo chicken embryo culture system suitable for imaging and microsurgery applications. J. Vis. Exp. doi: 10.3791/2154

Yap, C. H., Liu, X., and Pekkan, K. (2014). Characterization of the vessel geometry, flow mechanics and wall shear stress in the great arteries of wildtype prenatal mouse. PLoS ONE 9:e86878. doi: 10.1371/journal.pone.0086878

Yashiro, K., Shiratori, H., and Hamada, H. (2007). Haemodynamics determined by a genetic programme govern asymmetric development of the aortic arch. Nature 450, 285-288. doi: 10.1038/nature06254

Yelbuz, T. M., Choma, M. A., Thrane, L., Kirby, M. L., and Izatt, J. A. (2002). Optical coherence tomography: a new high-resolution imaging technology to study cardiac development in chick embryos. Circulation 106, 2771-2774. doi: 10.1161/01.CIR.0000042672.51054.7B

Yelbuz, T. M., Leatherbury, L., Johnson, M., Wolfe, R. R., and Kirby, M. L. (2000). Quantitative analyse der ventrikelfunktion imfrühen embryonalen herzen in "schalen-losen" kulturen nach ablation der neuralleiste. Z. Kardiol. 89, VI/26.

Yoshida, H., Manasek, F., and Arcilla, R. A. (1983). Intracardiac flow patterns in early embryonic life. A reexamination. Circ. Res. 53, 363-371.

Yoshigi, M., Knott, G. D., and Keller, B. B. (2000). Lumped parameter estimation for the embryonic chick vascular system: a time-domain approach using MLAB. Comput. Methods Programs Biomed. 63, 29-41. doi: 10.1016/S01692607(00)00061-4

Yu, Q., Shen, Y., Chatterjee, B., Siegfried, B. H., Leatherbury, L., Rosenthal, J., et al. (2004). ENU induced mutations causing congenital cardiovascular anomalies. Development 131, 6211-6223. doi: 10.1242/dev.01543

Zahka, K. G., Hu, N., Brin, K. P., Yin, F. C., and Clark, E. B. (1989). Aortic impedance and hydraulic power in the chick embryo from stages 18 to 29. Circ. Res. 64, 1091-1095.

Zamir, E. A., Czirok, A., Cui, C., Little, C. D., and Rongish, B. J. (2006). Mesodermal cell displacements during avian gastrulation are due to both individual cell-autonomous and convective tissue movements. 
Proc. Natl. Acad. Sci. U.S.A. 103, 19806-19811. doi: 10.1073/pnas.06061 00103

Zhang, X., Yelbuz, T. M., Cofer, G. P., Choma, M. A., Kirby, M. L., and Johnson, G. A. (2003). Improved preparation of chick embryonic samples for magnetic resonance microscopy. Magn. Reson. Med. 49, 1192-1195. doi: 10.1002/mrm.10460

Zheng, H. R., Liu, L. L., Williams, L., Hertzberg, J. R., Lanning, C., and Shandas, R. (2006). Real time multicomponent echo particle image velocimetry technique for opaque flow imaging. Appl. Phys. Lett. 88:261915. doi: 10.1063/1.2216875

Zhou, Y. Q., Foster, F. S., Parkes, R., and Adamson, S. L. (2003). Developmental changes in left and right ventricular diastolic filling patterns in mice. Am. J. Physiol. Heart Circ. Physiol. 285, H1563-H1575. doi: 10.1152/ajpheart.00384.2003

Zhou, Y. Q., Zhu, Y., Bishop, J., Davidson, L., Henkelman, R. M., Bruneau, B. G., et al. (2005). Abnormal cardiac inflow patterns during postnatal development in a mouse model of Holt-Oram syndrome. Am. J. Physiol. Heart Circ. Physiol. 289, H992-H1001. doi: 10.1152/ajpheart.00027.2005
Conflict of Interest Statement: The authors declare that the research was conducted in the absence of any commercial or financial relationships that could be construed as a potential conflict of interest.

Received: 18 April 2014; accepted: 02 October 2014; published online: 21 October 2014. Citation: Kowalski WJ, Pekkan K, Tinney JP and Keller BB (2014) Investigating developmental cardiovascular biomechanics and the origins of congenital heart defects. Front. Physiol. 5:408. doi: 10.3389/fphys.2014.00408

This article was submitted to Biophysics, a section of the journal Frontiers in Physiology.

Copyright (ㅇ 2014 Kowalski, Pekkan, Tinney and Keller. This is an open-access article distributed under the terms of the Creative Commons Attribution License (CC BY). The use, distribution or reproduction in other forums is permitted, provided the original author(s) or licensor are credited and that the original publication in this journal is cited, in accordance with accepted academic practice. No use, distribution or reproduction is permitted which does not comply with these terms. 